\title{
Analysis of the Elastic-Plastic Theoretical Model of the Pull-Out Interface between Geosynthetics and Tailings
}

\author{
Changbo Du $\mathbb{D}^{1}$ and $\mathrm{Fu} \mathrm{Yi} \mathbf{i}^{2,3}$ \\ ${ }^{1}$ College of Civil Engineering, Liaoning Technical University, Fuxin, Liaoning Province 123000, China \\ ${ }^{2}$ College of Architecture and Transportation, Liaoning Technical University, Fuxin, Liaoning Province 123000, China \\ ${ }^{3}$ China Coal Research Institute, Beijing 100013, China
}

Correspondence should be addressed to Changbo Du; duchangbo2839@163.com

Received 10 September 2019; Accepted 31 October 2019; Published 13 June 2020

Academic Editor: Xu Yang

Copyright (C) 2020 Changbo Du and Fu Yi. This is an open access article distributed under the Creative Commons Attribution License, which permits unrestricted use, distribution, and reproduction in any medium, provided the original work is properly cited.

\begin{abstract}
Aiming at the strain-hardening and strain-softening phenomena between geosynthetics and tailings during pull-out tests, bilinear and trilinear shear stress-displacement softening models were proposed. The pull-out process of the hardening reinforcement was divided into the elastic stage, elastic-hardening transition stage, and pure hardening stage. The pull-out process of the softened reinforcement was divided into the elastic stage, elastic-softening transition stage, pure softening stage, softening-residual transition stage, and pure residual stage. The expressions of the interface tension, shear stress, and displacement at the different stages under a pull-out load were derived through the interface basic control equation. At the same time, the evolution law of the interface shear stress at different pull-out stages was analysed, and the predicted results of the two elastic-plastic models were compared with the experimental results. The results show that the predicted results are in good agreement with the experimental data, which verifies the validity of the proposed two elastic-plastic models for the progressive failure analysis of reinforcement at the pull-out interface. During the process of pull-out, the transition stage is not obvious. When the reinforcement is in the elastic stage, the nonlinearity and maximum value of the interface shear stress increase with an increase in the elastic shear stiffness, while the tensile stiffness shows the opposite trend. When the reinforcement is in the hardening or softening stage, the larger the hardening (softening) shear stiffness is, the larger the change range of shear stress is and the more obvious the hardening (softening) characteristics of the reinforcement are. The results comprehensively reflect the progressive failure of reinforcementtailing interfaces with different strain types and provide theoretical support for the study of the interface characteristics of geosynthetic-reinforced tailings.
\end{abstract}

\section{Introduction}

The strain hardening and strain softening of geosynthetics are common mechanical properties of geosynthetics in reinforced engineering. This remarkable characteristic of geosynthetics has been emphasized in many experimental studies of the interface interactions between the reinforcement and soil $[1,2]$. Shi et al. [3] compared the reinforcement conditions of unidirectional and bidirectional geogrids and found that the pull-out curve of unidirectional geogrids tends to be strain softening, while the pull-out curve of bidirectional geogrids tends to be strain hardening. Generally, there are two kinds of mechanical tests to evaluate the interface properties of reinforced soil: the direct shear test and the pull-out test. However, in the analysis of the stability and interface interaction between the reinforcement and soil, the pull-out test [4] is more suitable because the stress and displacement in the pull-out test are gradually transferred from the pull-out end to the free end, which can fully reflect the interaction mechanism between the reinforcement and soil.

Generally, the relationship between the shear stress and displacement should be taken into account in the theoretical study of the interface characteristics between the reinforcement and soil [5-10]. Sobhi and $\mathrm{Wu}$ [11] proposed a pull-out interface model of retractable bars based on the 
elastic-plastic shear stress-displacement. Long et al. [12] used a parabolic fitting curve to describe the nonuniform shear distribution of the interface between the reinforcement and soil. Gurung et al. [13] and Misra et al. [14] used a hyperbolic model to analyse the relationship between the shear stress and displacement. Gurung [15] simplified the boundary conditions of the anchorage section on the basis of previous studies and obtained the stress and displacement solutions of the anchorage section by fitting the hyperbolic model. Esterhulzen et al. [16] proposed a hyperbolic displacement softening model before and after the peak value. Lin et al. [17] used linear simulations to simulate the plastic softening before and after the peak value and the shear stress and displacement changes in the plastic flow. Zhang et al. [18] proposed a three-stage elastic-plastic shear stress-displacement model, in which a hyperbolic model was used before the peak value, while a linear model was used to simulate the plastic softening and plastic flow after the peak value. Although the abovementioned interface model can effectively simulate pull-out behaviour, it fails to consider the interface progressive failure characteristics at different stages of the whole pull-out process.

To truly describe the progressive failure characteristics of the reinforcement-soil interface during different stages of the pull-out process, scholars worldwide have proposed some calculation models for the strain-softening characteristics of reinforcements. For example, Hong et al. [19] used the elastic-plastic theory model to study the progressive failure of the soil nail-soil interface under a pull-out state. Zhu et al. [20] and Chen et al. [21] deduced the analytical expressions of the axial force and shear stress at the reinforcement-soil interface at different pull-out stages through a three-parameter model. In the study of the interface characteristics of reinforcement-soil, there are few models for calculating the strain-hardening characteristics, and there is no computational model that includes both the strain hardening and strain softening of the reinforcement.

In this study, the strain hardening and strain softening of the pull-out curves between geosynthetics and tailings are investigated (hereafter referred to as strain-hardening reinforcement and strain-softening reinforcement). It is proposed that the hardening reinforcement undergoes three continuous stages during the pull-out process. Softening reinforcement goes through five continuous stages during the pull-out process. The distributions of the tension, shear stress, and displacement of two kinds of reinforcement at different pull-out stages are deduced. Moreover, the accuracy of the proposed two elastic-plastic pull-out models is verified by analysing and comparing the pull-out test results of two reinforcements. The evolution of the interface shear stress at different pull-out stages and its influencing factors are further studied.

\section{Analysis of the Pull-Out Test}

2.1. Test Instrument. The test instrument was a stripped-down YT1200 geosynthetic direct shear and pull-out system (Howard Nanjing Soil Instrument Manufacturing Company). The system mainly consisted of a test box (direct shear and pull-out), vertical loading system, horizontal loading system, and data acquisition system. The test equipment is shown in Figure 1. The inner dimensions of the pull-out test box were $300 \times 300 \times 220 \mathrm{~mm}$. A narrow slit with dimensions $300 \times 10 \mathrm{~mm}$ was opened in the middle of the front and back of the test groove to extract the geosynthetics. In the vertical loading system, the cylinder with a pressure sensor applied the overburden pressure through the reaction device. The cylinder was a $30 \mathrm{~L}$ air compressor. On top of the pressure loading system, there was a pressure plate with dimensions $295 \times 295 \times 10 \mathrm{~mm}$, which evenly applied overburden pressures within the range of $0-200 \mathrm{kPa}$. The tension and compression motor of the horizontal loading system with a tension sensor had a controllable rate, which can exert a constant loading speed in the range of $0-5 \mathrm{~mm} / \mathrm{min}$ and measure the test force. This machine was equipped with a control panel, which can set the overlying pressure, and the right side of the control panel was connected to the horizontal loading system, which can display the test results on a screen in real time and provide realtime monitoring of the test data for analysis or to stop the system in case of problems.

\subsection{Parameter Index of the Tailing Filling and Geosynthetics.} The tailing filler used in the test came from the tailing reservoir of Dazhong Co., Ltd. in Baotou City, Inner Mongolia. To reduce the influence of the water content in the sand on the test results, dry tailings were used. The density of tailings was $1.83 \mathrm{~g} /$ $\mathrm{cm}^{3}$, and the water content was $3.75 \%$. The physical properties of the tailings were as follows: the effective particle size $d_{10}=0.10 \mathrm{~mm}$, the median particle size $d_{30}=0.19 \mathrm{~mm}$, and the restricted particle size $d_{60}=0.30 \mathrm{~mm}$. The calculations showed that the unevenness coefficient of the tailings $C_{\mathrm{u}}$ was 3.5, and the curvature coefficient of the tailings $C_{\mathrm{c}}$ was 1.2. The latter value is between 1 and 3, which indicates that the tailings were of poor gradation. The particle grading curve is shown in Figure 2.

As shown in Figure 3, the geosynthetics used in the test are short-fibre needle-punched geotextiles (Figure 3(a)) and TGSG35 biaxial tension plastic geogrids (Figure 3(b)). These two geosynthetics have good application effects in various reinforcement projects. The concrete parameters of the reinforcement materials are shown in Table 1.

2.3. Test Principle. During the tests, when the geosynthetics were going to be pulled out, it was assumed that the shear stress on the upper and lower surfaces of the reinforcement was distributed evenly and met the equilibrium condition. The interface peak shear strength $\tau_{p}$ and the residual shear strength $\tau_{t}$ can be obtained by the following calculation:

$$
\begin{gathered}
\tau_{p}=\frac{T_{p}}{2 A_{\text {Interface }}}, \\
\tau_{r}=\frac{T_{r}}{2 A_{\text {Interface }}},
\end{gathered}
$$

where $\tau_{p}$ and $\tau_{r}$ are the peak shear strength and residual shear strength, $\mathrm{kPa}$, respectively; $T_{p}$ and $T_{r}$ are the maximum pull-out force and residual pull-out force, $\mathrm{kN}$, respectively; and $A_{\text {Interface }}$ is the area of the geosynthetics 


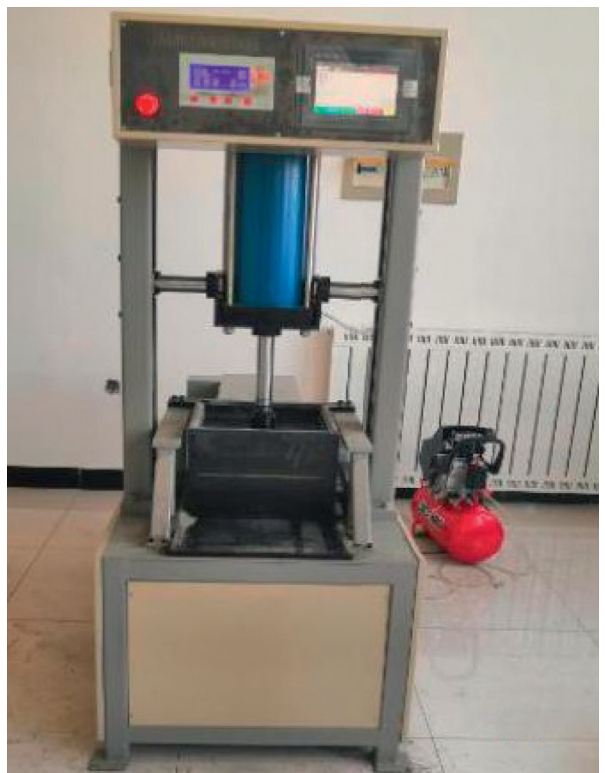

(a)
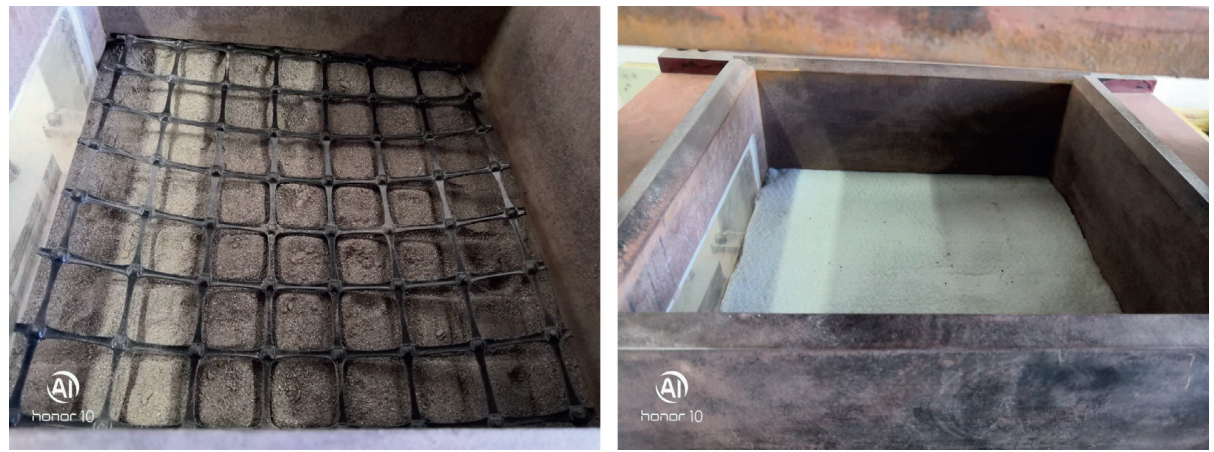

(b)
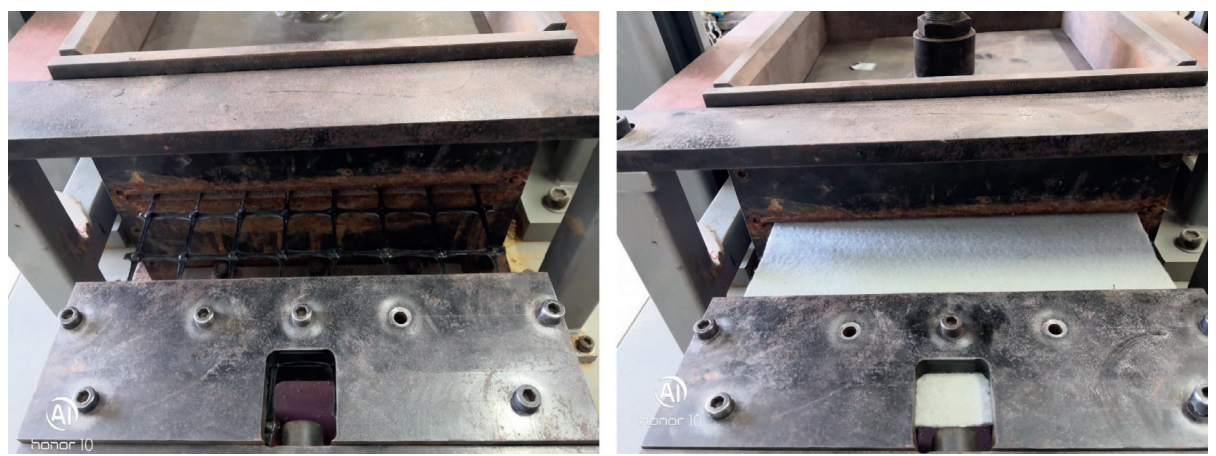

(c)

Figure 1: Pull-out test: (a) test device; (b) sample preparation and dimensions; (c) test setups.

embedded in the direct shear or pull-out test box, which is the area of the shear plane in the test process, $A_{\text {Interface }}=0.09 \mathrm{~m}^{2}$.

The pull-out tests were carried out under four different normal stresses $(10 \mathrm{kPa}, 20 \mathrm{kPa}, 30 \mathrm{kPa}$, and $40 \mathrm{kPa})$. The interface interaction between the reinforcement and soil can be described by the pseudofriction coefficient $f$, which is generally calculated as the ratio of the interface friction strength to the corresponding normal stress:

$$
\begin{aligned}
& f=\left(\frac{\tau_{p}}{\sigma_{n}}\right), \\
& f=\frac{\tau_{r}}{\sigma_{n}},
\end{aligned}
$$

where $\sigma_{n}=\left(q_{s}+\gamma h\right)$ is the normal stress, in which $q_{s}$ is the additional stress, $\gamma$ is the bulk density of the filler, and $h$ is the paving height of the filler (see Figure 4). 


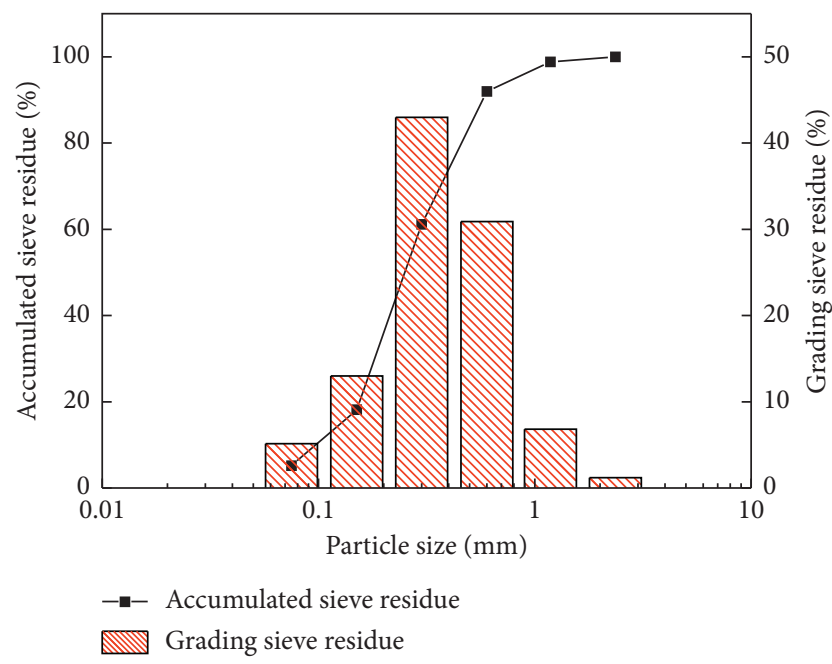

FIGURE 2: Gradation curve of the tailing sand.

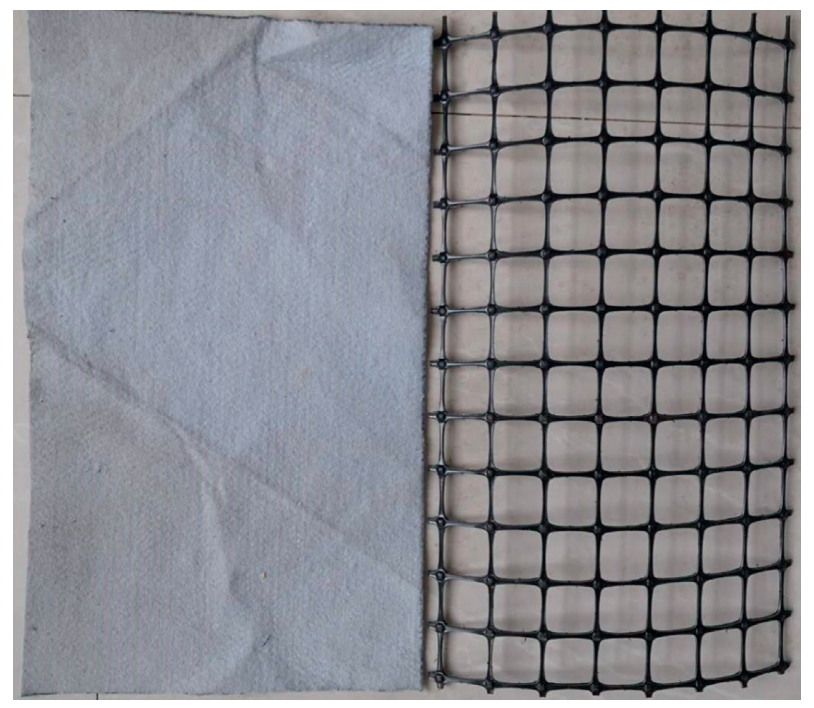

(a)

(b)

Figure 3: The geogrid used in the test: (a) geotextiles and (b) geogrid.

2.4. Test Method. To reduce the dispersion of the test results, 3 groups of parallel tests were conducted in each group. During the tests, the density of the tailing sand was used to control the amount of sand in the test box, and the sand loading process was stratified-compacted to ensure that each group had the same density. We simultaneously applied lubricating oil evenly on both sides of the pull-out test box to reduce the size effect during testing. The shear rate of the pull-out test is set to $2 \mathrm{~mm} / \mathrm{min}$ to eliminate the influence of the test rate on the results. The tests were performed in strict accordance with the "Test Methods of Geosynthetics for Highway Engineering (JTG E50-2012)” [22].

2.5. Analysis of the Test Results. The pull-out test results of the tailings and geogrids or geotextiles under different normal stresses are shown in Figure 5. In the pull-out test
TABLE 1: The technology parameters of the geogrids.

\begin{tabular}{|c|c|c|c|c|}
\hline $\begin{array}{l}\text { Mechanical } \\
\text { parameters of } \\
\text { the staple fibre } \\
\text { needling } \\
\text { geotextiles }\end{array}$ & $\begin{array}{l}\text { Technical } \\
\text { index }\end{array}$ & \multicolumn{2}{|c|}{$\begin{array}{l}\text { Mechanical } \\
\text { parameters of the } \\
\text { TGSG35 geogrid }\end{array}$} & $\begin{array}{c}\text { Technical } \\
\text { index }\end{array}$ \\
\hline $\begin{array}{l}\text { Longitudinal } \\
\text { and transverse } \\
\text { fracture strength } \\
\left(\mathrm{kN} \cdot \mathrm{m}^{-1}\right)\end{array}$ & 30 & $\begin{array}{l}\text { Tensile } \\
\text { strength } \\
\left(\mathrm{kN} \cdot \mathrm{m}^{-1}\right)\end{array}$ & $\begin{array}{c}\text { Radial, } \\
\text { zonal }\end{array}$ & 35 \\
\hline $\begin{array}{l}\text { Elongation } \\
\text { corresponding to } \\
\text { the standard } \\
\text { strength (\%) }\end{array}$ & $40 \sim 80$ & $\begin{array}{l}\text { Nominal } \\
\text { elongation }\end{array}$ & Radial & 15 \\
\hline $\begin{array}{l}\text { CBR breaking } \\
\text { strength } \geq(\mathrm{kN})\end{array}$ & 13 & & Zonal & 13 \\
\hline $\begin{array}{l}\text { Longitudinal } \\
\text { and transverse } \\
\text { tearing strength } \\
\geq(\mathrm{kN})\end{array}$ & 12 & $\begin{array}{c}\text { Tensile } \\
\text { strength at } \\
2 \%\end{array}$ & Radial & 12 \\
\hline $\begin{array}{l}\text { Equivalent } \\
\text { aperture }(\mathrm{mm})\end{array}$ & $0.05 \sim 0.2$ & $\begin{array}{c}\text { elongation } \geq \\
\left(\mathrm{kN} \cdot \mathrm{m}^{-1}\right)\end{array}$ & Zonal & 12 \\
\hline $\begin{array}{l}\text { Vertical } \\
\text { permeability } \\
\text { coefficient } \\
\left(\mathrm{cm} \cdot \mathrm{s}^{-1}\right)\end{array}$ & $1.0 \times 10^{-3}$ & $\begin{array}{c}\text { Tensile } \\
\text { strength at } \\
5 \% \\
\text { elongation } \geq\end{array}$ & Radial & 24 \\
\hline Thickness (mm) & 4.2 & $\left(\mathrm{kN} \cdot \mathrm{m}^{-1}\right)$ & Zonal & 24 \\
\hline
\end{tabular}

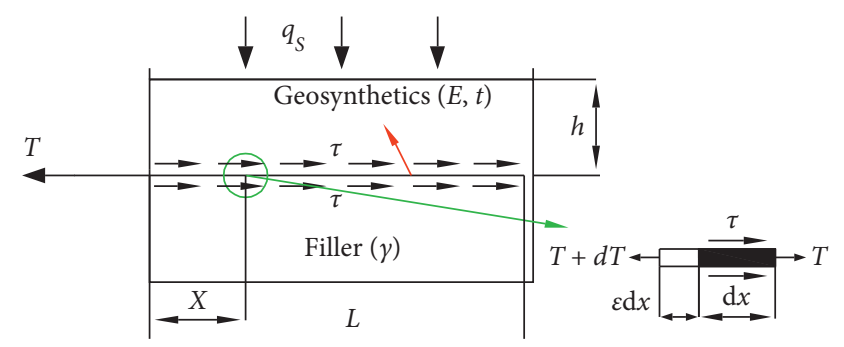

(a)

(b)

FIGURE 4: Pull-out sketch of the reinforcement: (a) overall stress of reinforcement and (b) force analysis of the microelement of reinforcement.

curve of the geogrids, the pull-out force increases with an increase in the pull-out displacement, but the rate of increase slows gradually, showing the characteristics of strain hardening as a whole. However, in the pull-out test curve of the geotextiles, the pull-out force rapidly reaches its peak value with an increase in the pull-out displacement and then decreases obviously, showing strain-softening characteristics. In addition, both kinds of pull-out curves require a certain pulling force at the beginning of pull-out because the reinforcement requires a certain pulling force to resist the friction of the interface between the reinforcement and tailings.

According to formula (2), the relationship between the pull-out pseudofriction coefficient and normal stress can be calculated, as shown in Figure 6. The pseudofriction coefficient between geogrids and geotextiles is negatively exponential to normal stress. With an increase in the normal stress, the pseudofriction coefficient decreases and the 


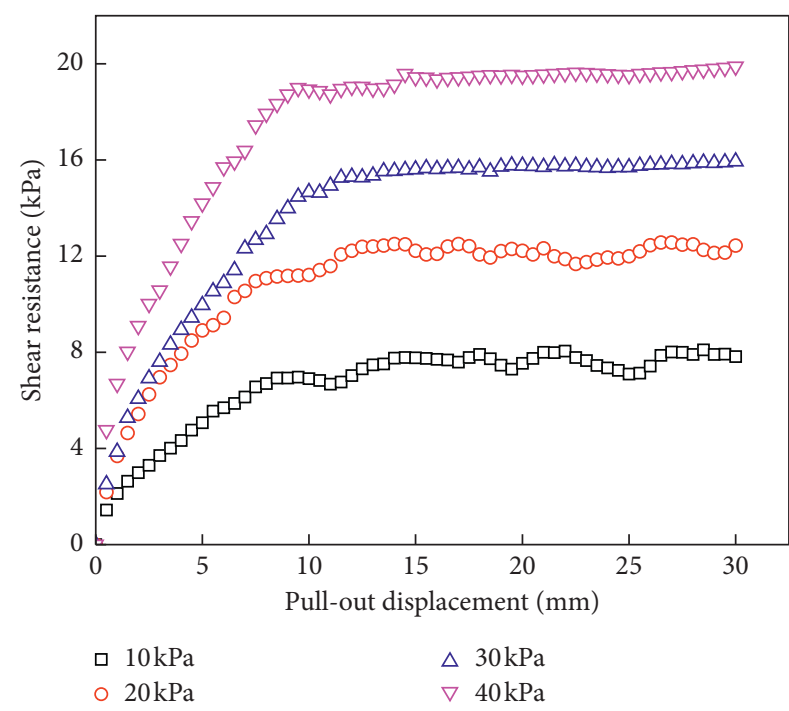

(a)

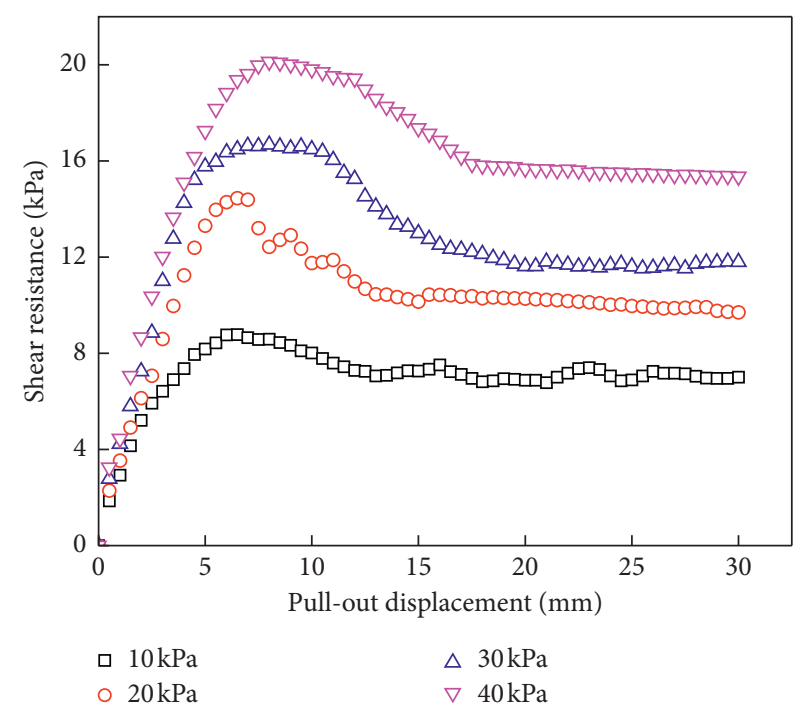

(b)

FIGURE 5: Pull-out test curves between geosynthetics and tailings: (a) geogrid and (b) geotextiles.

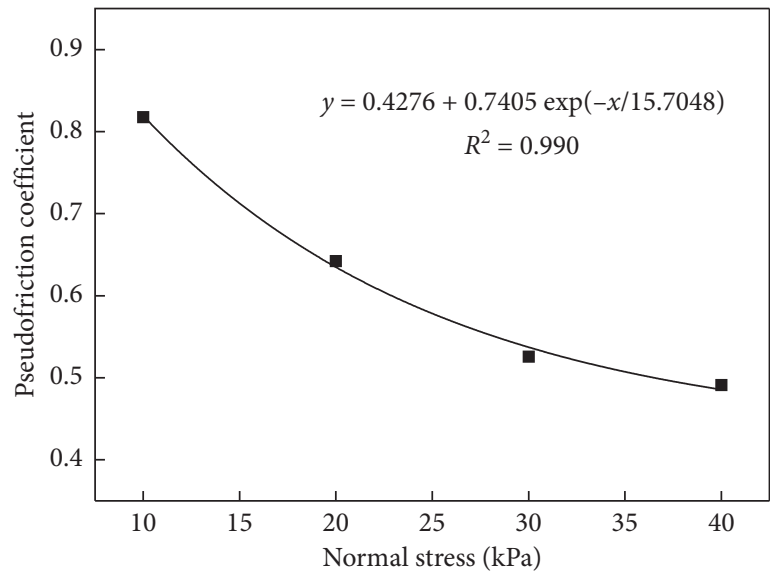

(a)

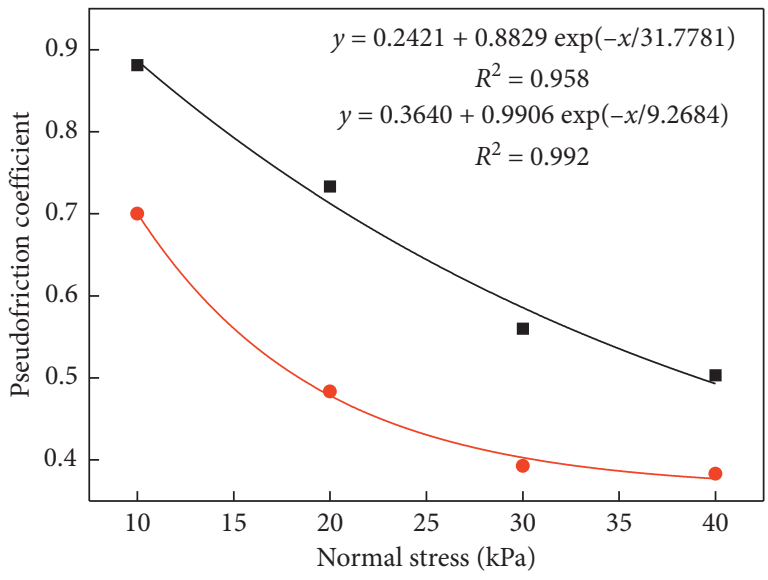

- Peak state

- Residual state

(b)

FIGURE 6: Relationship between the pull-out pseudofriction coefficient and normal stress: (a) geogrid and (b) geotextiles.

decreasing speed slows down gradually. The pseudofriction coefficient of geogrids is between 0.48 and 0.82 . The pseudofriction coefficient of geotextiles in the peak state is between 0.50 and 0.88 , the pseudofriction coefficient of geotextiles in the residual state is between 0.46 and 0.70 , and the difference between them is approximately $30 \%$ under the same normal stress condition.

\section{Elastic-Plastic Model of the Reinforcement- Tailing Interface}

3.1. Strain-Hardening Model of the Reinforcement. From the pull-out test results between geotextiles and tailings in Figure 5(a), it can be seen that the interface shear stress and the displacement curve of the strain-hardened reinforcement can be approximately expressed as an elastic relationship before reaching the peak value and then as strain-hardening characteristics. In this paper, the curve form is simplified to a bilinear shear stress-displacement relationship [23], as shown in Figure 7. It can be seen from the graph that the first stage (OA section) represents the relationship between the shear stress and displacement before the peak shear stress reaches a straight line, and the second stage ( $\mathrm{AB}$ section) represents the strain hardening of reinforcement by a straight line. In Figure $7, K_{s 1}$ and $K_{s 2}$ are the slopes of $\mathrm{OA}$ and $\mathrm{AB}$, which are also called the elastic interface shear stiffness and hardening shear stiffness, respectively; $\tau_{o}$ is the initial shear stress, and its value is the ratio of the initial pull-out force to the shear area, i.e., $\tau_{o}=T_{o} / 2 A ; \tau_{p}$ is the peak shear stress of the interface; and 


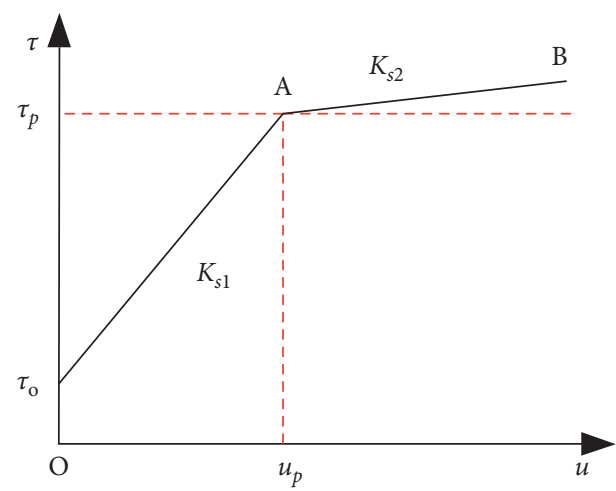

Figure 7: Relationship between the interface shear stress and the displacement of the bilinear $(\tau-u)$.

$u_{p}$ is the corresponding pull-out displacement, where $K_{s 1}=\left(\tau_{p}-\tau_{o}\right) / u_{p}$. When the shear stress increases to the ultimate shear stress of reinforcement, the failure of the reinforcement occurs. The ratio between them is defined as the failure ratio $R_{f}$ [18], i.e., $R_{f}=\tau_{p} / \tau_{\text {ult }}$, which generally has a value between 0.5 and 1.0 :

$$
\begin{aligned}
& \tau=K_{s 1} u+\tau_{o}, \quad 0 \leq u \leq u_{p}, \\
& \tau=K_{s 2}\left(u-u_{p}\right)+\tau_{p}, \quad u>u_{p} .
\end{aligned}
$$

\subsection{Strain-Softening Model of the Reinforcement.} According to the test results between the geogrid and tailings shown in Figure 5(b), the shear stress and the displacement curve of the strain-softening reinforcement interface can be approximately expressed as an elastic relationship before reaching the peak value and then as plastic softening and plastic flow. In this paper, the characteristic of this curve is simplified to a three-stage linear shear stress-displacement relationship [24], as shown in Figure 8. It can be seen from the figure that in the first stage $\left(\mathrm{O}^{\prime} \mathrm{A}^{\prime}\right)$, the relationship between the shear stress and displacement before shear stress reaches its peak value is represented by a straight line; in the second stage $\left(\mathrm{A}^{\prime} \mathrm{B}^{\prime}\right)$, the strain softening of reinforcement is represented by a straight line; and in the third stage $\left(\mathrm{B}^{\prime} \mathrm{C}^{\prime}\right)$, the plastic flow of reinforcement is represented by a horizontal straight line. In Figure $8, k_{s 1}$ is the slope of OA (the elastic shear stiffness), with $k_{s 1}=\left(\tau_{p}-\tau_{o}^{\prime}\right) / u_{p}$, where $\tau_{p}$ is the peak shear stress of the interface and $u_{p}$ is the corresponding displacement; $\tau_{o}^{\prime}$ is the initial shear stress, $\tau_{o}^{\prime}=T_{o} / 2 \mathrm{~A}$, where $T_{o}^{\prime}$ is the initial pull-out force; and $k_{s 2}$ is the slope of $\mathrm{AB}$ (softening shear stiffness) $k_{s 2}=\left(\left(\tau_{r}-\tau_{p}\right) /\right.$ $\left.\left(u_{r}-u_{p}\right)\right)<0$, where $\tau_{r}$ is the residual shear stress of the interface and $u_{r}$ is the corresponding displacement. The analogical damage ratio defines the ratio between $\tau_{r}$ and $\tau_{p}$ as $R_{f}$, that is, $R_{f}=\tau_{r} / \tau_{p}$ :

$$
\begin{aligned}
& \tau=k_{s 1}+\tau_{o}^{\prime} u, \quad 0 \leq u \leq u_{p}, \\
& \tau=k_{s 2}\left(u-u_{p}\right)+\tau_{p}, \quad u_{p}<u \leq u, \\
& \tau=R_{f} k_{s 1} u_{p}, \quad u>u_{r} .
\end{aligned}
$$

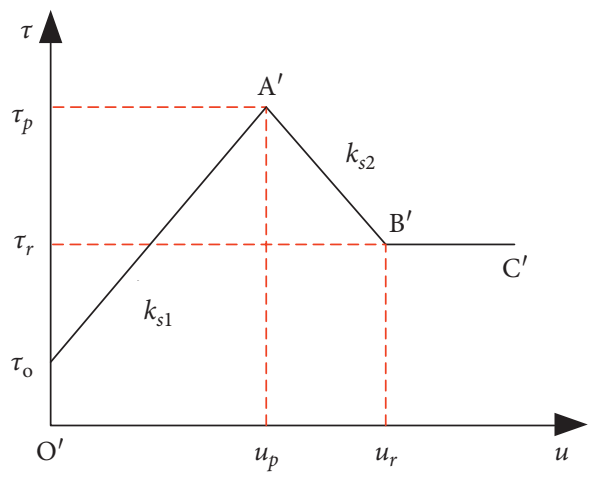

FIGURE 8: Relationship between the interface shear stress and the displacement of the trilinear $(\tau-u)$.

The suitability of the proposed model can be proven by referring to previous scholars' literature to increase the number of types of samples. Shi et al. [3] consider that the pull-out test curves of bidirectional plastic geogrids and different fillers (clay and sand) are generally strain hardening. Yang et al. [25] found that the pull-out curves are softening when studying the interface friction between geotextiles and loess. The suitability of the model can also be confirmed by the analysis of two mechanisms of geogridand geotextile-reinforced tailings. The main reason for strain hardening of geogrid-reinforced tailings is the blocking effect of the transverse rib of the geogrid. The strain-softening phenomenon of geotextile-reinforced tailings is due to the fact that when the pull-out force reaches the peak value with the increase of the pull-out displacement, the whole reinforcement undergoes sliding and strain-softening characteristics appear.

\section{Fundamental Equation of the Reinforcement- Soil Interface}

The pull-out test diagram of the reinforcement is shown in Figure 4 . In the test, the bottom of the test groove and the lateral boundary are fixed, and the vertical upward pressure can be applied on the bearing plate. The length and thickness of reinforcement are $L$ and $t$, respectively, and the tensile modulus is $E$. When the shear stress at $x$ is $\tau$, the microelement with length $\mathrm{d} x$ is taken for the analysis. The unit width of the reinforcement is taken as the width, and the boundary effect of the reinforcement is neglected. Then, according to the force balance, it can be concluded that

$$
(T+\mathrm{d} T)-T+2 \tau(\mathrm{d} x+\varepsilon \mathrm{d} x)=0,
$$

where $T$ is the tensile force per unit width of the reinforcement at $x, \varepsilon \mathrm{d} x$ is the deformation length of the microelement, and $\varepsilon$ is the strain.

Equation (5) can be rewritten as follows:

$$
\frac{\mathrm{d} T}{\mathrm{~d} x}+2 \tau(1+\varepsilon)=0
$$

The strain of reinforcement at $x$ can be written as follows: 


$$
\varepsilon=-\frac{\mathrm{d} u}{\mathrm{~d} x}
$$

where $u$ is the relative displacement of the reinforcement at $x$.

It is assumed that the strain is linearly correlated with the tensile force per unit width [21], i.e.,

$$
\varepsilon=\frac{T}{E t} \text {. }
$$

From Equations (5)-(8), we can obtain the following:

$$
E t \frac{\mathrm{d}^{2} u}{\mathrm{~d} x^{2}}+2 \tau(\varepsilon-1)=0 .
$$

In general, the actual $\varepsilon$ strain in the pull-out process is very small [25], which can be neglected. Therefore, Equation (9) is approximately expressed as follows:

$$
E t \frac{\mathrm{d}^{2} u}{\mathrm{~d} x^{2}}-2 \tau=0
$$

Equation (10) is the basic equation of the interface between the reinforcement and soil, and it is of great significance to the study of the friction characteristics of the interface between the reinforcement and soil.

\section{Pull-Out Interface Analysis of the Strain- Hardening Reinforcement}

5.1. Analysis of the Hardening Pull-Out Interface. Basic assumption: according to the definition of the theoretical model of the strain-hardening reinforcement, it is considered that the interface between the reinforcement and tailings will undergo an elastic stage, an elastic-hardening transition stage, and a pure hardening stage under a pull-out load, corresponding to stages I, II, and III in Figure 9, respectively. Through theoretical calculations, the expressions of the tension, shear stress, and displacement at each stage of pull-out can be obtained.

5.1.1. Elastic Stage (I Stage). When $0 \leq u<u_{p}$, the shear stress and displacement are elastic, which satisfies the equation $\tau=K_{s 1} u+\tau_{o}$. The governing equation of this stage can be obtained by the simultaneous Equations (10) and (3a):

$$
\frac{\mathrm{d}^{2} T}{\mathrm{~d} x^{2}}-\alpha^{2} T=0
$$

where $\alpha=\sqrt{2 K_{s 1} / E t}$.

Solving Equation (11), the following can be obtained:

$$
T_{e}(x)=C_{1} \exp (-\alpha x)+C_{2} \exp (\alpha x),
$$

where $T_{\mathrm{e}}(x)$ is the tension of the reinforcement at the elastic stage and $C_{1}$ and $C_{2}$ are the integral constants.

In the pull-out test, when the tension at the pull-out end, i.e., $x=0$, is $T_{0}$ and the tension at the free end, i.e., $x=L$, is 0 , the following boundary conditions exist:

$$
\left\{\begin{array}{l}
T(x=0)=T_{01}, \\
T(x=L)=0 .
\end{array}\right.
$$

By substituting the boundary condition (13) in Equation (12), we obtain

$$
\left\{\begin{array}{l}
C_{1}=\frac{\exp (\alpha L)}{\exp (\alpha L)-\exp (-\alpha L)} T_{01}, \\
C_{2}=\frac{-\exp (-\alpha L)}{\exp (\alpha L)-\exp (-\alpha L)} T_{01} .
\end{array}\right.
$$

The tension expression of stage I can be obtained as follows:

$$
T_{e}(x)=T_{01} \frac{\sinh \alpha(L-x)}{\sinh \alpha L} .
$$

According to Equations (10) and (3a), the corresponding shear stress and displacement relations can be obtained:

$$
\begin{aligned}
& \tau_{e}(x)=\frac{\alpha T_{01}}{2} \cdot \frac{\cosh \alpha(L-x)}{\sinh \alpha L}, \\
& u_{e}(x)=\frac{\alpha T_{01}}{2 K_{s 1}} \cdot \frac{\cosh \alpha(L-x)}{\sinh \alpha L} .
\end{aligned}
$$

The transformation of the pull-out displacement $u_{e 0}$ can be obtained by substituting $x=0$ into Equation (17):

$$
T_{01}=\frac{2 \tanh \alpha L}{\alpha} K_{s 1} u_{e 0}
$$

When $u_{e 0}=u_{p}$ and $\tau_{p}=K_{s 1} u_{e 0}+\tau_{o}$, from Equation (18), the critical tension $T_{e h 0}^{c}$ of the elastic stage and the elastic-hardening transition stage, i.e., the maximum tension in the elastic stage, can be obtained as follows:

$$
T_{e h 0}^{c}=\frac{2\left(\tau_{p}-\tau_{o}\right) \tanh \alpha L}{\alpha} .
$$

5.1.2. Elastic-Hardening Transition Stage (II Stage). With increasing tension, the interface shear stress gradually transfers from the pull-out end to the tail until it reaches its peak value. Then, the plastic characteristics of the pull-out end begin to occur, and the strain-hardening phenomenon occurs and enters the II stage. The critical point $P\left(x=L_{h}\right)$ is defined to divide the elastic zone and the hardening zone. When $0 \leq x<L_{h}$, the interface is in the stage II hardening zone, and when $L_{h}<x \leq L$, the interface is in the stage II elastic zone (where $L_{h}$ is the length of the hardening zone).

(1) Elastic Zone $\left(L_{h} \leq x \leq L\right)$.

The distributions of the interface tension, shear stress, and displacement in the stage II elastic zone are similar to those in the elastic stage; thus, we can obtain

$$
\begin{gathered}
T_{e}(x)=T_{02} \frac{\sinh \alpha(L-x)}{\sinh \alpha\left(L-L_{h}\right)}, \\
\tau_{e}(x)=\frac{\alpha T_{02}}{2} \cdot \frac{\cosh \alpha(L-x)}{\sinh \alpha\left(L-L_{h}\right)},
\end{gathered}
$$




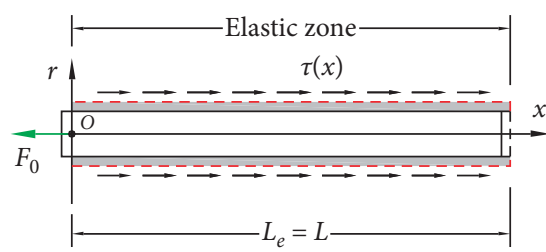

(a)

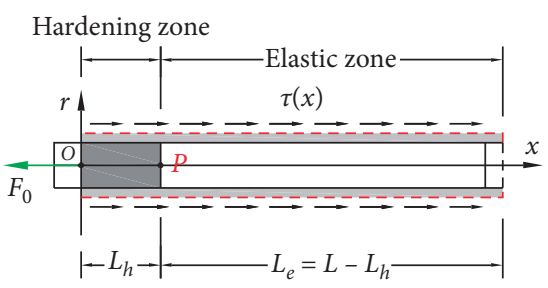

(b)

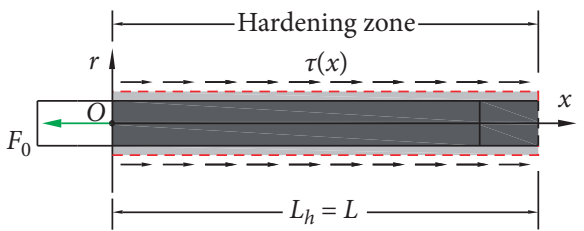

(c)

FIGURE 9: The progressive pull-out process of the strain-hardening reinforcement in the pull-out model analysis: (a) elastic stage; (b) elastichardening transition stage; (c) pure hardening stage.

$$
u_{e}(x)=\frac{\alpha T_{02}}{2 K_{s 1}} \cdot \frac{\cosh \alpha(L-x)}{\sinh \alpha\left(L-L_{h}\right)},
$$

where $T_{02}$ is the tension of the transition point $P$.

Considering that the interface shear stress at the transition point $P$ is equal to the peak shear stress, the following result can be obtained:

$$
T_{02}=\frac{2 \tau_{p} \tanh \alpha\left(L-L_{h}\right)}{\alpha} .
$$

\section{(2) Hardening Zone $\left(0 \leq x \leq L_{h}\right)$.}

The relationship between the interface shear stress and displacement in the stage II hardening zone is defined by Equation (3b), and the simultaneous Equations (10) and (3b) can be obtained as follows:

$$
\frac{\mathrm{d}^{2} T}{\mathrm{~d} x^{2}}-\beta^{2} T=0
$$

where $\beta=\sqrt{2 K_{\mathrm{s} 2} / E t}$.

Solving Equation (24) can yield

$$
T_{h}(x)=C_{3} \exp (-\beta x)+C_{4} \exp (\beta x),
$$

where $T_{h}(x)$ is the tension of reinforcement at the hardening zone of stage II and $C_{1}$ and $C_{2}$ are the integral constants.

Consider the boundary conditions as follows:

$$
\left\{\begin{array}{l}
T_{h}(x=0)=T_{03}, \\
T_{h}\left(x=L_{h}\right)=T_{e}\left(x=L_{h}\right) .
\end{array}\right.
$$

By substituting the boundary condition (26) in Equation (25), we can obtain

$$
\left\{\begin{array}{l}
C_{3}=-T_{03} \frac{\exp \left(-\beta L_{h}\right)}{\exp \left(\beta L_{h}\right)-\exp \left(-\beta L_{h}\right)}+\frac{2 \tau_{p} \tanh \alpha\left(L-L_{h}\right)}{\alpha\left[\exp \left(\beta L_{h}\right)-\exp \left(-\beta L_{h}\right)\right]}, \\
C_{4}=T_{03} \frac{\exp \left(\beta L_{h}\right)}{\exp \left(\beta L_{h}\right)-\exp \left(-\beta L_{h}\right)}-\frac{2 \tau_{p} \tanh \alpha\left(L-L_{h}\right)}{\alpha\left[\exp \left(\beta L_{h}\right)-\exp \left(-\beta L_{h}\right)\right]} .
\end{array}\right.
$$

The expressions of the tension, shear stress, and displacement in stage II can be obtained as follows:

$$
\begin{aligned}
T_{h}(x)= & T_{03} \frac{\sinh \beta\left(L_{h}-x\right)}{\sinh \beta L_{h}}+\frac{2 \tau_{p} \tanh \alpha\left(L-L_{h}\right)}{\alpha} \cdot \frac{\sinh \beta x}{\sinh \beta L_{h}}, \\
\tau_{h}(x)= & \frac{\beta T_{03}}{2} \cdot \frac{\cosh \beta\left(L_{h}-x\right)}{\sinh \beta L_{h}}-\frac{\beta \tau_{p} \tanh \alpha\left(L-L_{h}\right)}{\alpha} \cdot \frac{\cosh \beta x}{\sinh \beta L_{h}}, \\
u_{h}(x)= & \frac{\beta T_{03}}{2 K_{s 2}} \cdot \frac{\cosh \beta\left(L_{h}-x\right)}{\sinh \beta L_{h}}-\frac{\beta \tau_{p} \tanh \alpha\left(L-L_{h}\right)}{\alpha K_{s 2}} \\
& \frac{\cosh \beta x}{\sinh \beta L_{h}}-\frac{\tau_{p}}{K_{s 2}}+u_{p} .
\end{aligned}
$$

Since the shear stress at the transition point $P$ between the elastic zone and the hardening zone is continuous, i.e., $\tau_{e}\left(x=L_{h}\right)=\tau_{h}\left(x=L_{h}\right)$, the following can be obtained:

$$
T_{03}=\frac{2 \tau_{p} \sinh \beta L_{h}}{\beta}+\frac{2 \tau_{p} \tanh \alpha\left(L-L_{h}\right)}{\alpha} \cdot \cosh \beta L_{h} .
$$

When $L_{h}=L$, the critical tension $T_{h 0}^{c}$ between the elastic-hardening transition stage and the pure hardening stage can be obtained by Equation (31):

$$
T_{h 0}^{c}=\frac{2 \tau_{p} \sinh \beta L}{\beta} .
$$

5.1.3. Pure Hardening Stage (III Stage). Similar to the analysis of the hardening zone of stage II, Equation (25) is still applicable to the pure hardening stage, and the boundary conditions are as follows: 


$$
\left\{\begin{array}{l}
T_{s}(x=0)=T_{04} \\
T_{s}(x=L)=0 .
\end{array}\right.
$$

The expressions of the interface tension, shear stress, and displacement at the pure hardening stage are as follows:

$$
\begin{aligned}
& T_{h}(x)=T_{04} \cdot \frac{\sinh \beta(L-x)}{\sinh \beta L}, \\
& \tau_{h}(x)=\frac{\beta T_{04}}{2} \cdot \frac{\cosh \beta(L-x)}{\sinh \beta L}, \\
& u_{h}(x)=\frac{\beta T_{04}}{2 K_{s 2}} \cdot \frac{\cosh \beta(L-x)}{\sinh \beta L}-\frac{\tau_{p}}{K_{s 2}}+u_{p} .
\end{aligned}
$$

Let $x=0$ be substituted into Equation (36) to obtain the transformation of the pull-out displacement $u_{h 0}$ at this stage:

$$
T_{04}=\frac{2 \tanh \beta L}{\beta}\left[K_{\mathrm{s} 2}\left(u_{h 0}-u_{p}\right)+\tau_{p}\right] .
$$

In the pure hardening stage, the interface pull-out force and shear stress at the pull-out end all increase. When the shear stress at the pull-out end increases to the ultimate stress $\tau_{\text {ult }}$ of the reinforcement, the reinforcement is destroyed. Then, $\tau_{\text {ult }}=K_{s 2}\left(u_{h 0}-u_{p}\right)+\tau_{p}$, combined with $R_{f}=\tau_{p} / \tau_{\text {ult }}$, so Equation (37) can be written as follows:

$$
T_{04}=\frac{2 \tau_{p} \tanh \beta L}{R_{f} \beta} .
$$

In summary, closed solutions are obtained for the three stages of the pull-out process of strain-hardening reinforcement. The critical tension and the initial tension between the two stages are shown in Tables 2 and 3.

5.2. Verification of the Hardening Model. To verify the elastic-plastic theoretical model of strain hardening, the pull-out test results between geogrids and tailings mentioned above are used for the simulation, and the predicted results are shown in Figure 10. According to the graph, the prediction results are in good agreement with the pull-out test results, and the model can effectively describe the progressive pull-out behaviour of geogrids in the tailings. Moreover, the displacement of stage II is relatively small compared with that of stages I and III, which is due to the large elastic modulus and the small length of reinforcement, resulting in the progressive failure of the reinforcement not obvious. This transitional stage can be neglected in the analysis of the pull-out behaviour of geogrids in the tailings.

Furthermore, to better understand the five pull-out stages of geogrids in the tailings, the relationship between the interface shear stiffness (elastic shear stiffness $K_{s 1}$ and hardening shear stiffness $K_{s 2}$ ) and the initial shear stress with the normal stress is given, as shown in Figure 11. With an increase in the normal stress, $K_{s 1}$ and $K_{s 2}$ increase linearly. The initial shear stress is also linearly related to the normal stress, and the initial shear strength index can be obtained from the Mohr-Coulomb strength criterion.

5.3. Distribution of the Interface Shear Stress. To visually reflect the stress evolution law of strain-hardening reinforcement at different stages of the pull-out interface, the interface shear stress distribution at three stages was analysed. The model parameters selected according to the above test results are shown in Table 4 . To simplify the analysis, the model parameters were normalized. The normalized reinforcement position was $X=x / L$, and the normalized interface shear stress was $\rho=\tau / \tau_{p}$.

The parameters $\tau_{p}=\sigma_{n} f=15.78 \mathrm{kPa}, \alpha=\sqrt{2 K_{s 1} / E t}=$ 1.20 , and $\beta=\sqrt{2 K_{s 2} / E t}=0.26$ were calculated. According to the model parameters given, the following formulas were substituted.

5.3.1. Elastic Stage. Substitution of Equation (16) can yield $\tau_{e}(x)=\tau_{p}(\cosh \alpha(L-x) / \cosh \alpha L), \quad$ i.e., $\quad \rho=(\cosh \alpha(1-$ $X) / \cosh \alpha L)$.

The substitution of Equation (19) indicates that the critical tension of the elastic stage and the elastic-hardening transition stage is $T_{e h 0}^{c}=\left(2 \tau_{p} \tanh \alpha L / \alpha\right)=9.08 \mathrm{kN} / \mathrm{m}$.

\subsubsection{Elastic-Hardening Transition Stage}

(i) Elastic Zone $(0.5 \leq X \leq 1)$.

The substitution of $L_{h}=L / 2$ into Equation (64) yields $\tau_{e}(x)=\tau_{p} \tanh (\alpha L / 2)(\cosh \alpha(L-x) / \sinh (\alpha L / 2)), \quad$ i.e., $\rho=(\cosh \alpha L(1-X) / \cosh (\alpha L / 2))$.

(ii) Hardening Zone $(0 \leq X \leq 0.5)$.

The substitution of $L_{h}=L / 2$ into Equation (29) results in $\tau_{h}(x)=\tau_{p} \cdot \cosh \beta((L / 2)-x)+\left(\tau_{p} \beta \tanh (\alpha L / 2) / \alpha \sinh (\beta L /\right.$ $2)) \cdot[\cosh (\beta L / 2) \cdot \cosh \beta((L / 2)-x)-\cosh \beta x]$, i.e., $\rho=\cosh$ $\beta L(0.5-X)+(\beta \tanh (\alpha L / 2) / \alpha \sinh (\beta L / 2)) \cdot[\cosh (\beta L / 2)$. $\cosh \beta L(0.5-X)-\cosh \beta L X]$.

From Equation (32), the critical tension of the elastichardening transition stage and the pure hardening stage is $T_{h 0}^{c}=\left(2 \tau_{p} \sinh \beta L / \beta\right)=9.48 \mathrm{kN} / \mathrm{m}$.

(iii) Pure Hardening Stage.

The substitution of Equation (35) results in $\tau_{h}(x)=\tau_{p}\left(\cosh \beta(L-x) / R_{f} \cosh \beta L\right)$, i.e., $\rho=(\cosh \beta L(1-$ $\left.X) / R_{f} \cosh \beta L\right)$.

The substitution of Equation (38) shows that the ultimate tensile force at the stage of pure hardening is $T_{04}=\left(2 \tau_{p} \tanh \beta L / R_{f} \beta\right)=11.81 \mathrm{kN} / \mathrm{m}$.

According to the above expression of the interface shear stress, the evolution law of the shear stress in the three stages of elastic, elastic-hardening transition, and pure hardening of the strain-hardening reinforcement can be obtained, as shown in Figure 12.

When $T \leq 9.08 \mathrm{kN} / \mathrm{m}$, the interface is in the elastic stage, and the shear stress decreases nonlinearly from the pull-out end to the free end. When $T=9.08 \mathrm{kN} / \mathrm{m}$, the interface is in 
TABle 2: Critical tensile force between the two stages of the hardening pull-out model.

\begin{tabular}{llr}
\hline Pull-out stage & I-II & II-III \\
\hline Critical tensile force & $T_{e h 0}^{c}=\left(2 \tau_{p} \tanh \alpha L\right) / \alpha$ & $T_{h 0}^{c}=\left(2 \tau_{p} \sinh \beta L\right) / \beta$ \\
\hline
\end{tabular}

TABLE 3: Initial tensile forces at different stages of the hardening pull-out model.

\begin{tabular}{lcll}
\hline Pull-out stage & I & II (elastic zone, hardening zone) & III \\
\hline $\begin{array}{l}\text { Initial tensile } \\
\text { forces }\end{array}$ & \multirow{2}{*}{$T_{01}=((2 \tanh \alpha L) / \alpha) K_{s 1} u_{e 0}$} & $T_{02}=\left(2 \tau_{p} \tanh \alpha\left(L-L_{h}\right)\right) / \alpha$, \\
$T_{03}=\left(\left(2 \tau_{p} \sinh \beta L_{h}\right) / \beta\right)+\left(\left(2 \tau_{p} \tanh \alpha\left(L-L_{h}\right)\right) / \alpha\right) \cdot \cosh \beta L_{h}$ & $T_{04}=\left(2 \tau_{p} \tanh \beta L\right) / R_{f} \beta$ \\
\hline
\end{tabular}

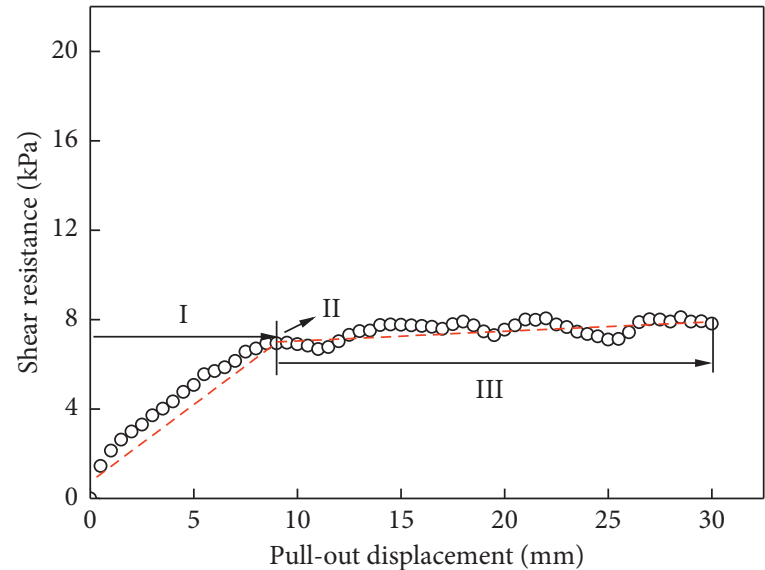

(a)

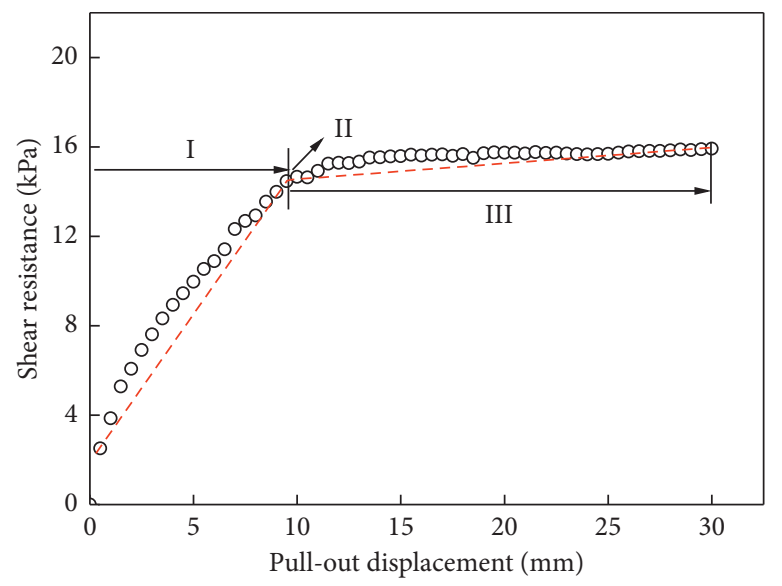

(c)

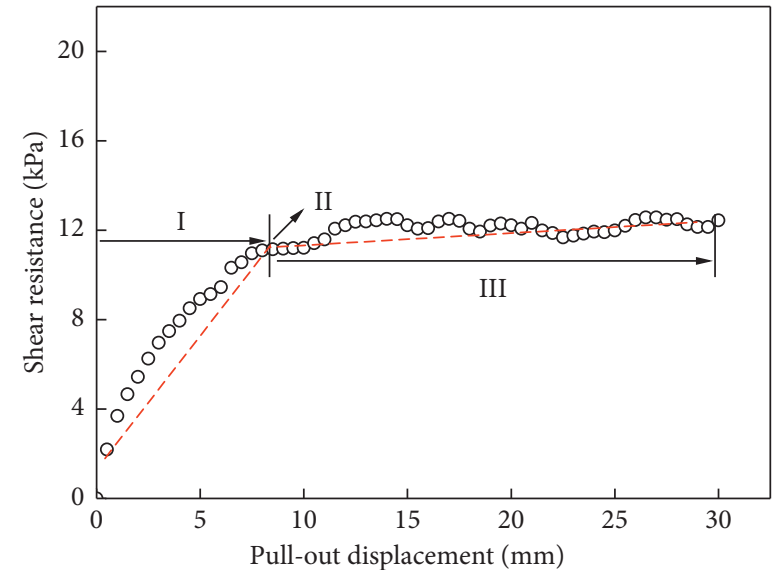

(b)

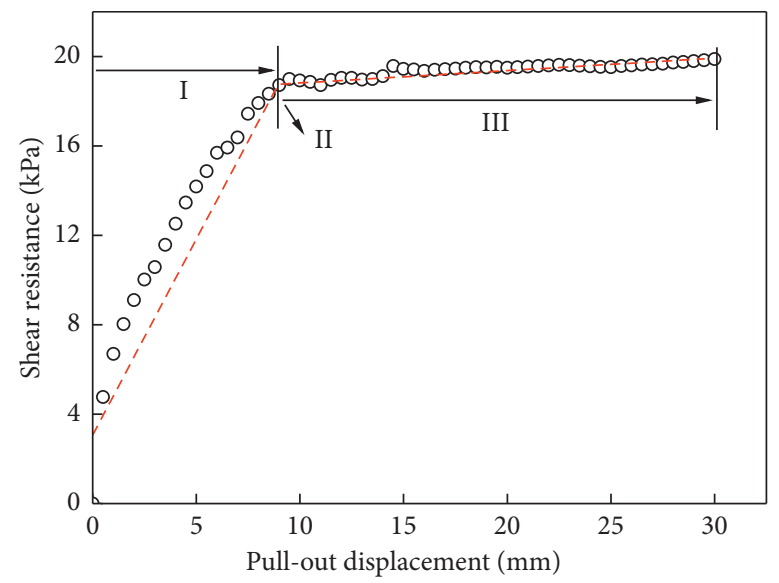

(d)

FIGURE 10: Comparison between the pull-out test results and model-predicted results of geogrids under different normal stresses: (a) $10 \mathrm{kPa}$; (b) $20 \mathrm{kPa}$; (c) $30 \mathrm{kPa}$; and (d) $40 \mathrm{kPa}$.

the critical stage of elastic and pure hardening, and the peak shear stress reaches $20 \mathrm{kPa}$ at the pull-out end.

When $9.08 \mathrm{kN} / \mathrm{m} \leq T \leq 9.48 \mathrm{kN} / \mathrm{m}$, the interface is in the transition stage of elastic-hardening, in which the shear stress at the pull-out end reaches its peak value and then drives the free end to continue to increase. The shear stress decreases from the pull-out end to the free end. When $T=9.48 \mathrm{kN} / \mathrm{m}$, the free end also reaches its peak value, and the interface will enter the stage of pure hardening.
When $9.48 \mathrm{kN} / \mathrm{m} \leq T \leq 11.81 \mathrm{kN} / \mathrm{m}$, the interface is in the stage of pure hardening, and the shear stress at the pullout end continues to increase until $T=11.81 \mathrm{kN} / \mathrm{m}$, when the shear stress at the pull-out end reaches the ultimate stress and the reinforcement is damaged.

5.4. Parametric Impact Analysis. From the above analysis, it can be seen that the interface shear stress is mainly affected by the elastic shear stiffness $\left(K_{s 1}\right)$ and the tensile stiffness $(E t)$ 


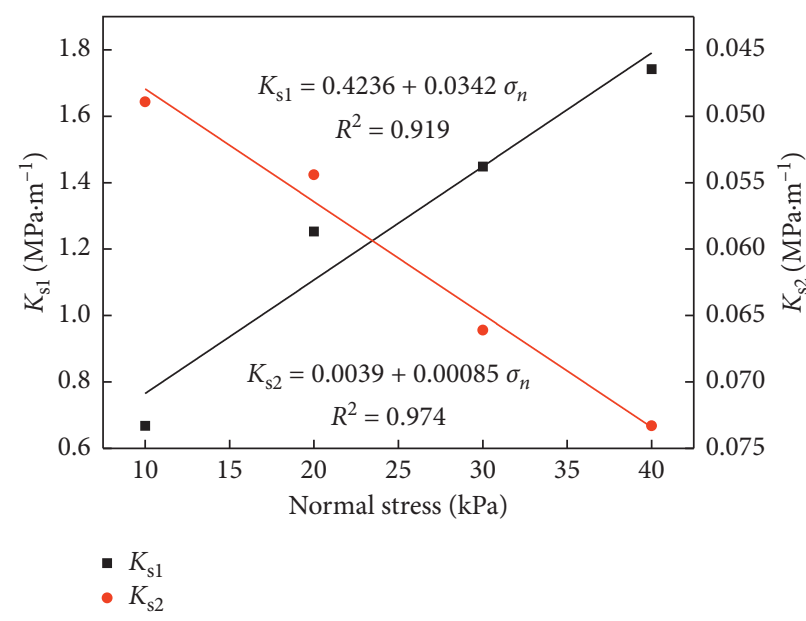

(a)

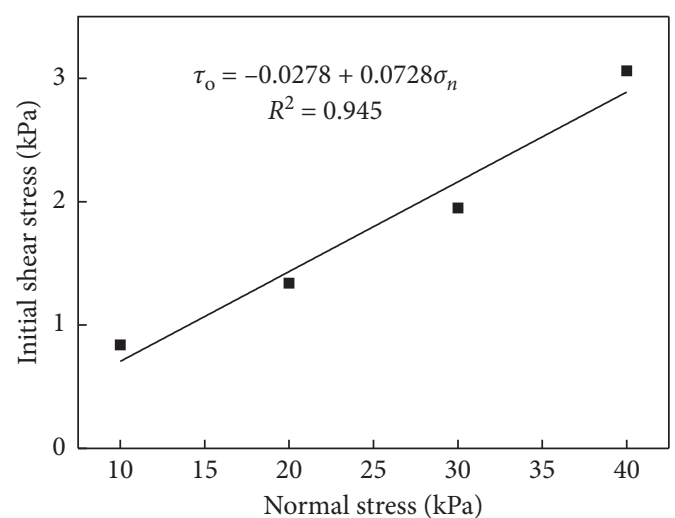

(b)

Figure 11: The relationship between the normal stress and shear stiffness of the hardening model: (a) shear stiffness; (b) initial shear stress.

TABLE 4: Hardening model parameters.

\begin{tabular}{lccccccc}
\hline$\sigma_{n}(\mathrm{kPa})$ & $L(\mathrm{~m})$ & $t(\mathrm{~mm})$ & $E(\mathrm{GPa})$ & $K_{s 1}(\mathrm{MPa} / \mathrm{m})$ & $K_{s 2}(\mathrm{MPa} / \mathrm{m})$ & $f$ & $R_{f}$ \\
\hline 30 & 0.3 & 2 & 1 & 1.449 & 0.066 & 0.526 & 0.8 \\
\hline
\end{tabular}

in the elastic stage, and the distribution of shear stress in the hardening stage is related to the length of the hardening zone $\left(L_{h}\right)$ and the hardening shear stiffness $\left(K_{s 2}\right)$. The calculated parameters are consistent with those in the previous section, in which the ratio of the hardening zone length to the reinforcement length is defined as $\eta=L_{h} / L$.

5.4.1. Elastic Stage. The effect of the elastic shear stiffness $\left(K_{s 1}\right)$ on the interface shear stress at different locations of the reinforcement in stage I is shown in Figure 13. The distribution of the interface shear stress in the elastic stage decreases nonlinearly from the pull-out end to the free end. The maximum shear stress is the same, which is the peak shear stress. The larger the $K_{s 1}$ is, the more obvious the nonlinearity of the interface shear stress curve is.

The effect of the single-width tensile stiffness $(E t)$ on the interface shear stress at different locations of the reinforcement in stage I is shown in Figure 14. It can be seen from the graph that the distribution of the interface shear stress decreases nonlinearly at this stage, but the smaller is the $E t$, the more obvious is the nonlinearity of the curve, which is due to the negative correlation between $E t$ and $K_{s 1}$ $\left(\alpha=\sqrt{2 K_{s 1} / E t}\right)$.

5.4.2. Elastic-Hardening Transition Stage. The influence of the hardening zone length $L_{p}(\eta)$ on the interface shear stress at different locations of the reinforcement in stage II is shown in Figure 15. It can be found from the graph that the interface shear stress in the elastic-hardening transition stage decreases nonlinearly in both the elastic zone and the hardening zone. The maximum shear stress is at the pull-out end, and the minimum shear stress is at the free end. The critical point of the two points is the transition point. The nonlinearity of the shear stress curve in the elastic zone is more obvious than that in the hardening zone.

The effect of the hardening shear stiffness $\left(K_{s 2}\right)$ on the interface shear stress at different locations of the reinforcement in stage II is shown in Figure 16. It can be seen from the graph that $K_{s 2}$ only affects the change in the shear stress in the hardening zone of stage II but has no effect on the change in the shear stress in the elastic zone. The larger the $K_{s 2}$ is, the larger the range of the shear stress curve in the hardening zone is.

5.4.3. Pure Hardening Stage. The effect of the hardening shear stiffness $\left(K_{s 2}\right)$ on the interface shear stress at different locations of the reinforcement in stage III is shown in Figure 17. It can be found from the graph that the larger the $K_{s 2}$ is, the greater the sag of the interface shear stress curve in stage III is. In practice, $K_{s 2}$ is very small. In the elastichardening transition stage, the shear stress at the pull-out end should be slightly larger than the peak shear stress and then slowly decrease until the shear stress at the pull-out end reaches the ultimate shear stress and the reinforcement is damaged.

\section{Pull-Out Interface Analysis of the Strain- Softening Reinforcement}

6.1. Analysis of the Softening Pull-Out Interface. Basic assumption: the pull-out process of the strain-softening reinforcement under the pull-out load is divided into five stages [24]: the elastic stage, elastic-softening transition stage, pure softening stage, softening-residual transition stage, and pure residual stage, corresponding to stages I, II, III, IV, and V in Figure 18, respectively. The expressions of 


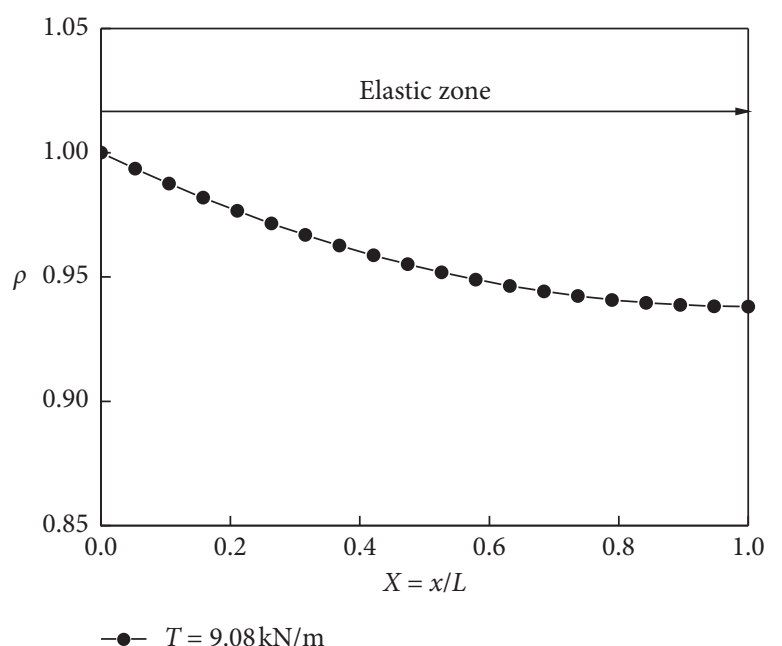

(a)

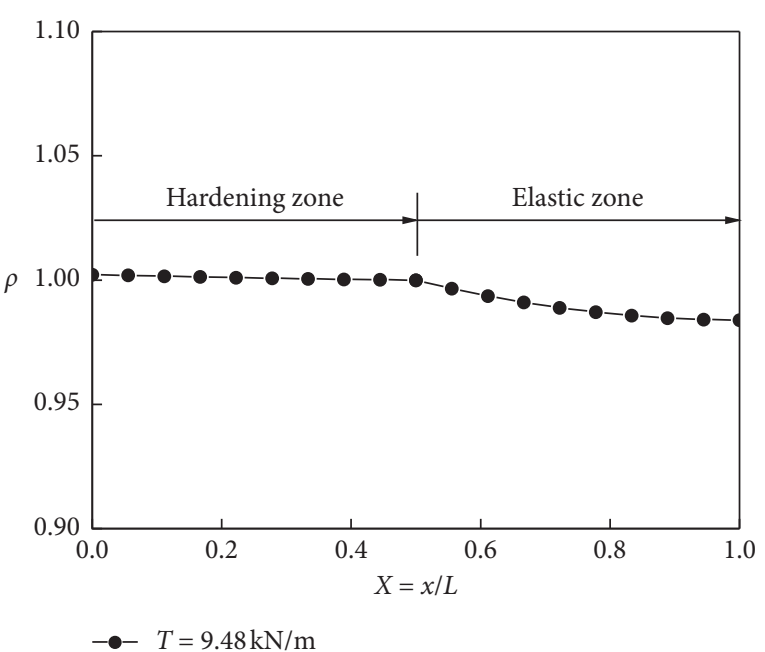

(b)

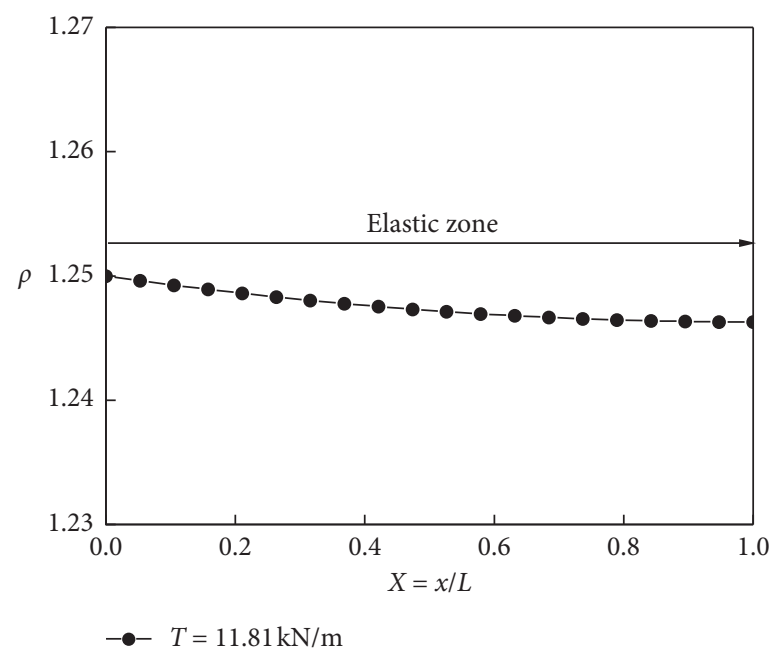

(c)

FIGURE 12: Evolution of the interfacial shear stress in different stages of the pull-out process of the reinforced tailings (strain-hardening reinforcement): (a) elastic stage; (b) elastic-hardening transition stage; (c) pure hardening stage.

the interfacial tension, shear stress, and displacement at the different stages of pull-out can be obtained by theoretical calculations.

6.1.1. Elastic Stage (I Stage). Similar to the distribution law of the strain-hardening reinforcement in the elastic stage, the expressions of the tension, shear stress, and displacement at this stage can be obtained by Equations (10) and $(4 a)$ :

$$
\begin{aligned}
& T_{e}(x)=T_{01} \cdot \frac{\sinh \alpha(L-x)}{\sinh \alpha L}, \\
& \tau_{e}(x)=\frac{\alpha T_{01}}{2} \cdot \frac{\cosh \alpha(L-x)}{\sinh \alpha L}, \\
& u_{e}(x)=\frac{\alpha T_{01}}{2 k_{s 1}} \cdot \frac{\cosh \alpha(L-x)}{\sinh \alpha L} .
\end{aligned}
$$

In Equation (41), $x=0$ can be substituted to obtain the transformation of the pull-out displacement $u_{e 0}$ :

$$
T_{01}=\frac{2 \tanh \alpha L}{\alpha} k_{s 1} u_{e 0}
$$

when $u_{e 0}=u_{p}$ and $\tau_{p}=k_{s 1} u_{e 0}+\tau_{o}$, the critical tension $T_{e h 0}^{c}$ of the elastic and elastic-softening transition stages can be obtained from Equation (42), that is, the maximum tension in the elastic stage,

$$
T_{e s 0}^{c}=\frac{2\left(\tau_{p}-\tau_{o}\right) \tanh \alpha L}{\alpha} .
$$

6.1.2. Elastic-Softening Transition Stage (II Stage). With increasing tension, the interface shear stress gradually transfers from the pull-out end to the tail until it reaches its peak value. Then, the plastic characteristics of the pullout end begin to occur, and the strain-hardening 


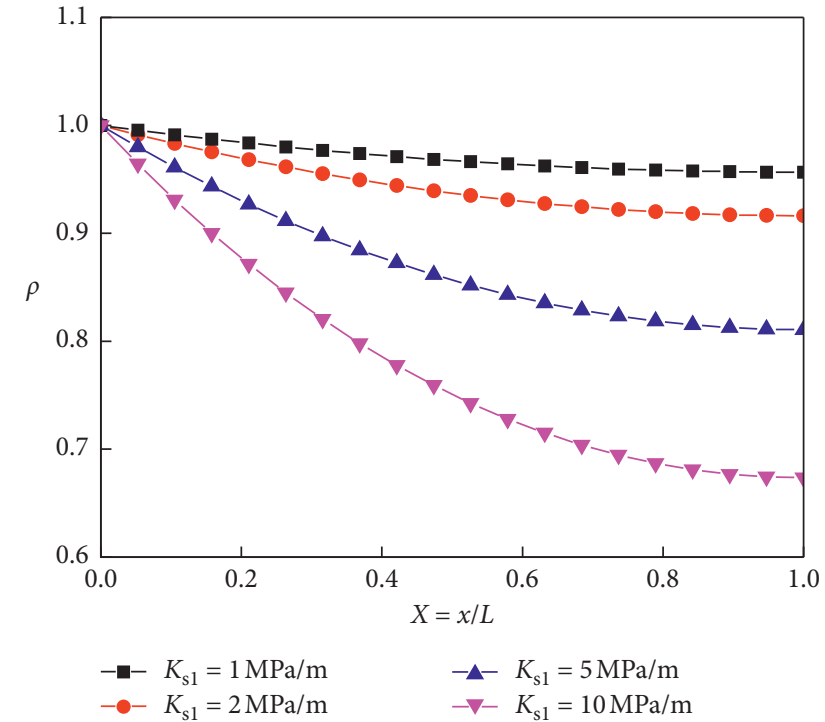

Figure 13: Effect of the interface frictional resistance at stage I on $K_{s 1}$.

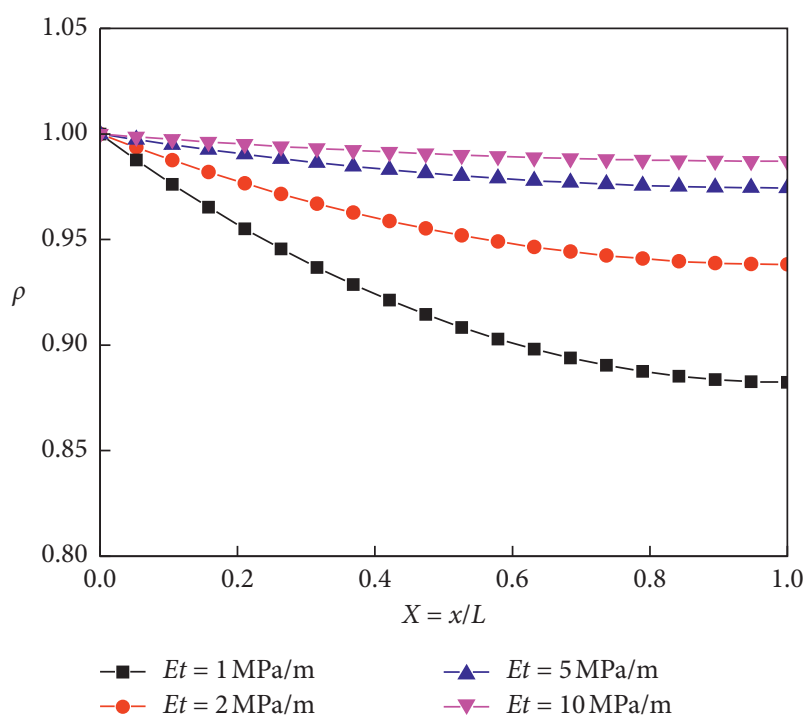

FIGURE 14: Effect of the interface frictional resistance at stage I on Et.

phenomenon occurs and enters the II stage. The critical point $P\left(x=L_{h}\right)$ is defined to divide the elastic zone and the hardening zone. When $0 \leq x<L_{h}$, the interface is in the stage II hardening zone, and when $L_{h}<x \leq L$, the interface is in the stage II elastic zone (where $L_{h}$ is the length of the hardening zone).

\section{(1) Elastic Zone $\left(L_{s} \leq x \leq L\right)$.}

The distributions of the interface tension, shear stress, and displacement in the stage II elastic zone are similar to those in the elastic stage:

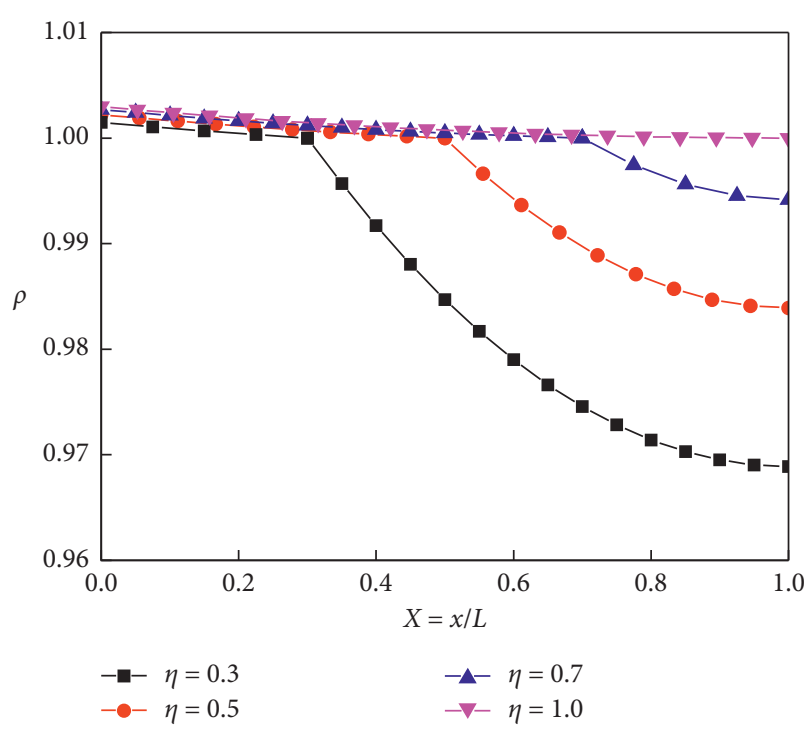

FIGURE 15: Effect of the interface frictional resistance at stage II on $L_{p}$.

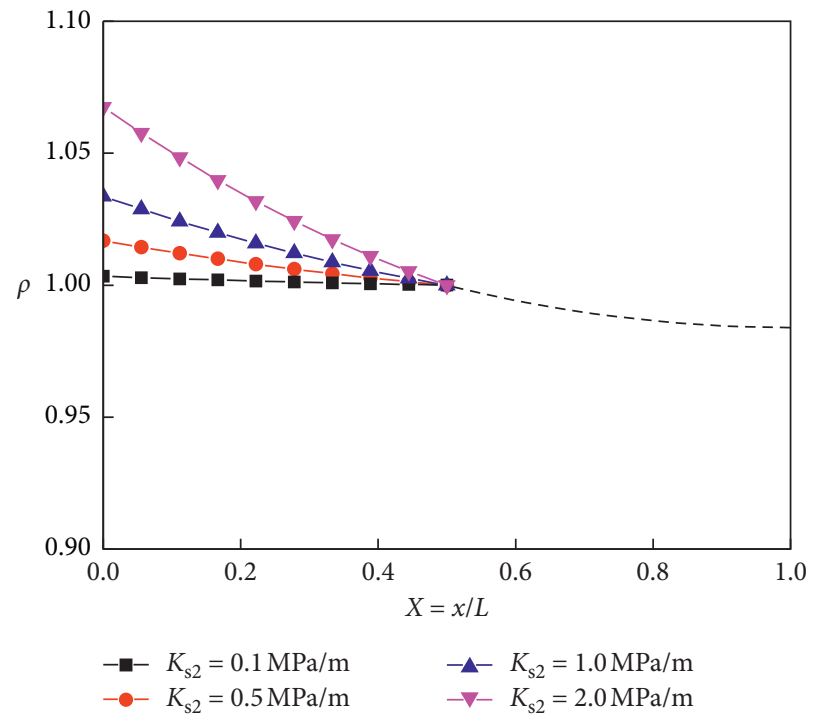

FIGURE 16: Effect of the interfacial frictional resistance at stage II on $K_{s 2}$.

$$
\begin{aligned}
& T_{e}(x)=T_{02} \cdot \frac{\sinh \alpha(L-x)}{\sinh \alpha\left(L-L_{s}\right)}, \\
& \tau_{e}(x)=\frac{\alpha T_{02}}{2} \cdot \frac{\cosh \alpha(L-x)}{\sinh \alpha\left(L-L_{s}\right)}, \\
& u_{e}(x)=\frac{\alpha T_{02}}{2 k_{s 1}} \cdot \frac{\cosh \alpha(L-x)}{\sinh \alpha\left(L-L_{s}\right)},
\end{aligned}
$$

where $T_{02}$ is the pull-out force of the transition point $P$.

Considering that the interface shear stress of the transition point $Q_{1}$ is equal to the peak shear stress, the following can be obtained: 


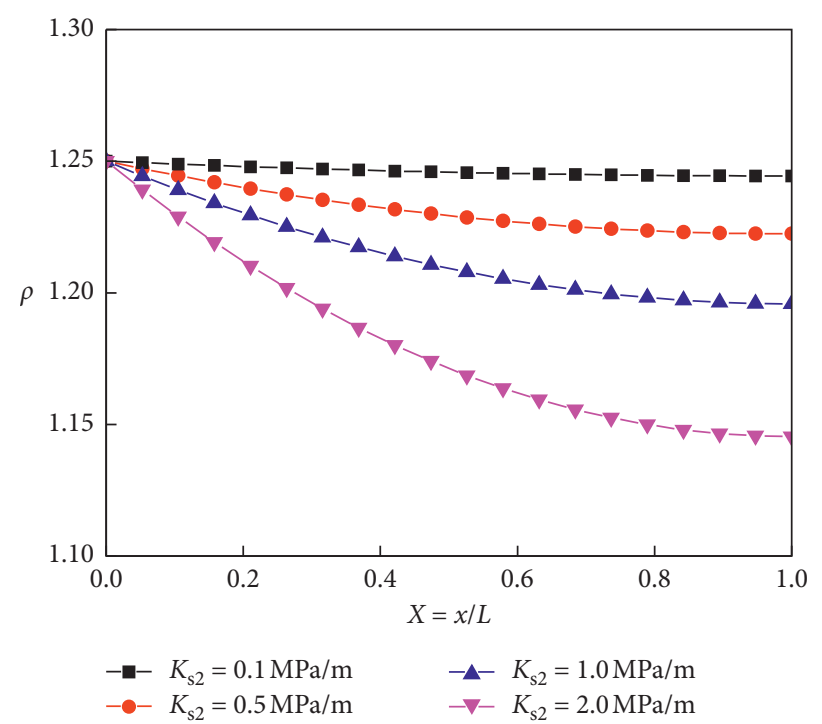

FIGURE 17: Effect of the interfacial frictional resistance at stage III on $K_{s 2}$.

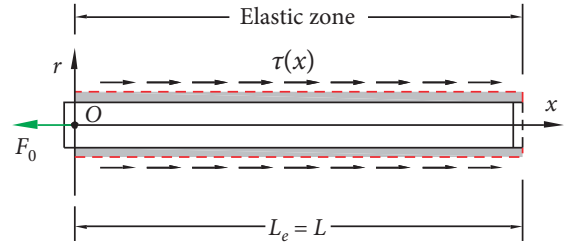

(a)

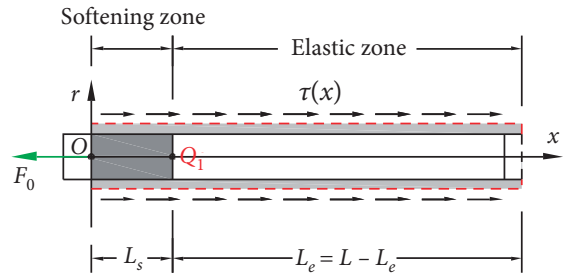

(b)

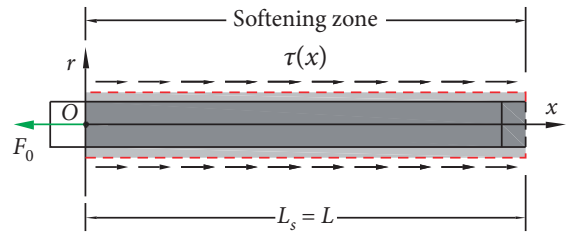

(c)

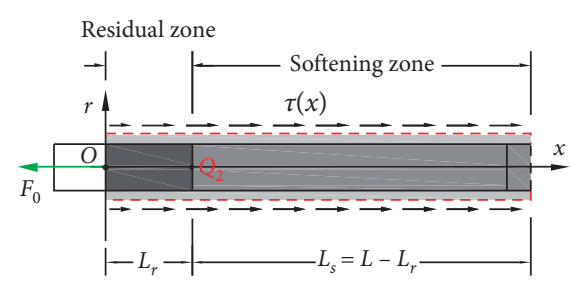

(d)

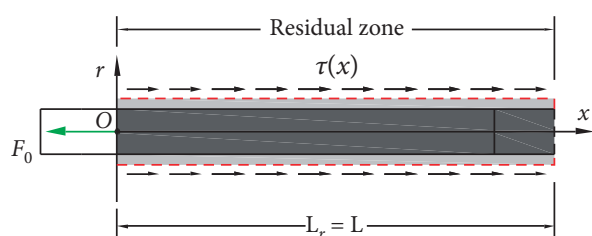

(e)

FIGURE 18: The progressive pull-out process of strain-softening reinforcement in the pull-out model analysis: (a) elastic stage; (b) elasticsoftening transition stage; (c) pure softening stage; (d) softening-residual transition stage; and (e) pure residual stage.

$$
T_{02}=\frac{2 \tau_{p} \tanh \alpha\left(L-L_{s}\right)}{\alpha}
$$

(2) Softening Zone $\left(0 \leq x \leq L_{s}\right)$.

The relationship between the interface shear stress and the displacement in the softening zone is defined by Equation (4b). The simultaneous Equations (10) and (4b) can be obtained as follows:

$$
\frac{\mathrm{d}^{2} T}{\mathrm{~d} x^{2}}+\beta^{2} T=0,
$$

where $\beta=\sqrt{-2 k_{s 2} / E t}>0$.

Solving Equation (48) can yield

$$
T_{s}(x)=C_{3} \cos (\beta x)+C_{4} \sin (\beta x),
$$

where $T_{s}(x)$ is the tension of the reinforcement at the elastic stage and $C_{3}$ and $C_{4}$ are the integral constants.

Consider the following boundary conditions:

$$
\left\{\begin{array}{l}
T_{s}(x=0)=T_{03}, \\
T_{s}\left(x=L_{s}\right)=T_{e}\left(x=L_{s}\right) .
\end{array}\right.
$$

The substitution of Equation (47) into Equation (46) results in

$$
\left\{\begin{array}{l}
C_{3}=T_{03}, \\
C_{4}=\frac{2 \tau_{p} \tanh \alpha\left(L-L_{s}\right)}{\alpha \sin \beta L_{s}}-T_{03} \cot \beta L_{s} .
\end{array}\right.
$$

Since the shear stress at the transition point $Q_{1}$ between the elastic zone and the softening zone is continuous, i.e., 
$\tau_{e}\left(x=L_{s}\right)=\tau_{s}\left(x=L_{s}\right)$, it can be determined that $T_{03}$ is as follows:

$$
T_{03}=2 \tau_{p}\left[\frac{\sin \beta L_{s}}{\beta}+\frac{\tanh \alpha\left(L-L_{s}\right)}{\alpha} \cos \beta L_{s}\right] .
$$

The expressions of the interface tension, shear stress, and displacement in stage II can be obtained:

$$
T_{s}(x)=2 \tau_{p}\left[\frac{\sin \beta\left(L_{s}-x\right)}{\beta}+\frac{\tanh \alpha\left(L-L_{s}\right)}{\alpha} \cos \beta\left(L_{s}-x\right)\right],
$$

$\tau_{s}(x)=\tau_{p}\left[\cos \beta\left(L_{s}-x\right)-\frac{\beta \tanh \alpha\left(L-L_{s}\right)}{\alpha} \sin \beta\left(L_{s}-x\right)\right]$,

$$
\begin{aligned}
u_{s}(x)= & \frac{\tau_{p}}{k_{s 2}}\left[\cos \beta\left(L_{s}-x\right)-\frac{\beta \tanh \alpha\left(L-L_{s}\right)}{\alpha} \sin \beta\left(L_{s}-x\right)\right] \\
& -\frac{\tau_{p}}{k_{s 2}}+u_{p},
\end{aligned}
$$

when $L_{s}=L$, the critical pull-out force $T_{s 0}^{c}$ of the elasticsoftening transition stage and the pure softening stage can be obtained from Equation (52):

$$
T_{s 0}^{c}=\frac{2 \tau_{p} \sin \beta L}{\beta} \text {. }
$$

6.1.3. Pure Softening Stage (III Stage). Similar to the analysis of the stage II softening zone, Equation (50) is still applicable to the pure softening stage with the following boundary conditions:

$$
\left\{\begin{array}{l}
T_{s}(x=0)=T_{04} \\
T_{s}(x=L)=0
\end{array}\right.
$$

The solution of the pure softening stage is as follows:

$$
\begin{aligned}
T_{s}(x) & =T_{04}(\cos \beta x-\cot \beta L \sin \beta x), \\
\tau_{s}(x) & =\frac{\beta T_{04}}{2}(\sin \beta x+\cot \beta L \cos \beta x), \\
u_{s}(x) & =\frac{\beta T_{04}}{2 k_{s 2}}(\sin \beta x+\cot \beta L \cos \beta x)-\frac{\tau_{p}}{k_{s 2}}+u_{p} .
\end{aligned}
$$

Let $x=0$ be substituted into Equation (60) to obtain the transformation of the pull-out displacement $u_{s 0}$ at this stage:

$$
T_{04}=\frac{2 \tan \beta L}{\beta}\left[k_{s 2}\left(u_{s 0}-u_{p}\right)+\tau_{p}\right] \text {. }
$$

In the pure softening stage, the interface tension and shear stress decrease. When $u_{s 0}=u_{r}$ and $\tau_{r}=k_{\mathrm{s} 2}\left(u_{s 0}-u_{p}\right)+\tau_{p}$, the critical pull-out force $T_{s r 0}^{c}$ of the elastic-softening transition stage and the pure softening stage can be obtained from Equation (61); that is, the minimum pull-out force of the pure softening stage is

$$
T_{s r 0}^{\mathcal{c}}=\frac{2 \tau_{r} \tan \beta L}{\beta} .
$$

6.1.4. Softening-Residual Transition Stage (IV Stage). When the pull-out force decreases to $T_{s r 0}^{c}$, the pull-out end of the reinforcement begins to enter the residual state and gradually extends when the end of reinforcement enters stage IV. The transition point $Q_{2}\left(x=L_{r}\right)$ is defined to divide the softening zone and the residual zone. When $0 \leq x<L_{r}$, the interface is in the residual zone of stage II, and when $L_{r}<x \leq L$, the interface is in the softening zone of stage II ( $L_{r}$ is the residual zone length).

(1) Softening Zone $\left(L_{s} \leq x \leq L\right)$.

The distributions of the tension, shear stress, and displacement in the pure softening stage are similar to those in the softening-residual transition stage $\left(x \longrightarrow x-L_{r}\right.$, $L \longrightarrow L-L_{r}$, and $\left.T_{04} \longrightarrow T_{05}\right)$. According to Equations (58)-(60), the relationship of the tension, shear stress, and displacement in the elastic zone of stage IV can be obtained:

$$
T_{s}(x)=T_{05}\left[\cos \beta\left(x-L_{r}\right)-\cot \beta\left(L-L_{r}\right) \sin \beta\left(x-L_{r}\right)\right],
$$

$$
\tau_{s}(x)=\frac{\beta T_{05}}{2}\left[\sin \beta\left(x-L_{r}\right)+\cot \beta\left(L-L_{r}\right) \cos \beta\left(x-L_{r}\right)\right],
$$

$$
\begin{aligned}
u_{s}(x)= & \frac{\beta T_{05}}{2 k_{s 2}}\left[\sin \beta\left(x-L_{r}\right)+\cot \beta\left(L-L_{r}\right) \cos \beta\left(x-L_{r}\right)\right] \\
& -\frac{\tau_{p}}{k_{s 2}}+u_{p} .
\end{aligned}
$$

Since the interface shear stress at the transition point $Q_{2}$ is equal to the residual shear stress $\tau_{s}\left(x-L_{r}\right)=\tau_{r}$, it can be obtained according to Equation (64):

$$
T_{05}=\frac{2 \tau_{r} \tan \beta\left(L-L_{r}\right)}{\beta} .
$$

(2) Residual Zone $\left(0 \leq x \leq L_{r}\right)$.

The interface shear stress in the residual zone is equal to the residual shear strength, which can be obtained by Equations (10) and (4c):

$$
\frac{\mathrm{d} T}{\mathrm{~d} x}=-2 \tau_{r} .
$$

Consider the boundary conditions:

$$
\left\{\begin{array}{l}
T_{r}(x=0)=T_{06}, \\
T_{r}\left(x=L_{r}\right)=T_{s}\left(x=L_{r}\right) .
\end{array}\right.
$$

It can be obtained as follows: 


$$
\begin{aligned}
T_{06} & =\frac{2 \tau_{r} \tan \beta\left(L-L_{r}\right)}{\beta}+2 \tau_{r} L_{r}, \\
T_{r}(x) & =2 \tau_{r}\left(L_{r}-x\right)+\frac{2 \tau_{r} \tan \beta\left(L-L_{r}\right)}{\beta}, \\
u_{r}(x) & =\frac{\tau_{r}}{E t} x^{2}-\frac{2 \tau_{r}}{E t}\left[L_{r} x+\frac{\tan \beta\left(L-L_{r}\right)}{\beta} x\right]+C_{5},
\end{aligned}
$$

where

$$
C_{5}=\frac{\tau_{r} L_{r}^{2}}{E t}-\frac{2 \tau_{r} L_{r}}{\beta E t} \tan \beta\left(L-L_{r}\right)+\frac{\tau_{r}-\tau_{p}}{k_{s 2}}+u_{p} .
$$

The critical tension of the softening-residual transition stage and the pure residual stage is obtained at $x=0$, and the result of the substitution of $L_{r}=L$ into Equation (69) is as follows:

$$
T_{s 0}^{c}=2 \tau_{r} L
$$

6.1.5. Pure Residual Stage (V Stage). The critical shear displacement at the pull-out end of the reinforcement is obtained by substituting $x=0$ and $L_{r}=L$ into Equation (71):

$$
u_{r 0}^{c}=\frac{\tau_{r} L^{2}}{E t}+\frac{\tau_{r}-\tau_{p}}{k_{s 2}}+u_{p}
$$

Assuming that the displacement of the reinforcement at the pull-out end is $u_{0}^{\prime}$, the distribution of the shear displacement can be derived as follows:

$$
\begin{gathered}
u_{r}(x)=\frac{\tau_{r}}{E t}\left(x^{2}-L^{2}\right)-\frac{2 \tau_{r} L}{E t}(x-L)+\frac{\tau_{r}-\tau_{p}}{k_{s 2}}+u_{p} \\
+\left(u_{0}^{\prime}-u_{r 0}^{c}\right)=u_{0}^{\prime}+\frac{2 \tau_{r} L}{E t}\left(x^{2}-2 L x\right) .
\end{gathered}
$$

At this stage, the tension $T_{r 0}^{c}$ and the interface shear stress $\tau_{r}$ remain constant. Therefore, the distribution of tension at different locations of the reinforcement is as follows:

$$
T_{r}(x)=2 \tau_{r}(L-x) .
$$

In summary, closed solutions are obtained for the five stages of the pull-out process of strain-hardening reinforcement. The critical tension and the initial tension between the two stages are shown in Tables 5 and 6.

6.2. Verification of the Softening Model. To verify the elasticplastic theoretical model of strain softening, the pull-out test results between geotextiles and tailings mentioned above are used for simulation, and the predicted results are shown in Figure 19. The predicted results are in good agreement with the pull-out test results, and the model can effectively describe the pull-out behaviour of geotextiles in the tailings. Moreover, the displacements of the II and IV stages are relatively smaller than those of the I, III, and V stages, so the two transitional stages can be neglected in the analysis of the pull-out behaviour of the geotextiles in the tailings.

In addition, to better understand the five pull-out stages of the geotextiles in the tailings, the relationship between the interface shear stiffness (elastic shear stiffness $k_{s 1}$ and softening shear stiffness $k_{s 2}$ ) and the initial shear stress with the normal stress is given, as shown in Figure 20. The graph shows that $k_{s 1}$ and $k_{s 2}$ increase linearly with an increase in the normal stress, and the initial shear stress is linearly related to the normal stress. The initial shear strength index can be obtained by the Mohr-Coulomb strength criterion.

6.3. Distribution of the Interface Shear Stress Values. To visually reflect the stress evolution law of strain-softening reinforcement at different stages of the pull-out interface, the interface shear stress distribution at three stages was analysed. The model parameters selected according to the above test results are shown in Table 7 . To simplify the analysis, the model parameters were normalized. The normalized reinforcement position is $X=x / L$, and the normalized interface shear stress is $\rho=\tau / \tau_{p}$.

The parameters $\tau_{p}=\sigma_{n} f=16.80 \mathrm{kPa}, \quad \tau_{r}=R_{f} \tau_{p}=$ $11.76 \mathrm{kPa}, \alpha=\sqrt{2 k_{s 1} / E t}=1.48$, and $\beta=\sqrt{-2 k_{s 2} / E t}=0.67$ are calculated. According to the model parameters given, the following formulas are substituted:

6.3.1. Elastic Stage. The substitution of Equation (40) can yield $\tau_{e}(x)=\tau_{p}(\cosh \alpha(L-x) / \cosh \alpha L)$, i.e., $\rho=(\cosh \alpha$ $(1-X) / \cosh \alpha L)$.

The substitution of Equation (43) shows that the critical tension of the elastic stage and the elastic-softening transition stage is $T_{e s 0}^{c}=\left(2 \tau_{p} \tanh \alpha L / \alpha\right)=9.47 \mathrm{kN} / \mathrm{m}$.

\subsubsection{Elastic-Softening Transition Stage}

Elastic Zone $(0.5 \leq X \leq 1)$.

Let $L_{s}=L / 2$ in Equation (45) produce $\tau_{e}(x)=$ $\tau_{p}(\cosh \alpha(L-x) / \cosh (\alpha L / 2))$, i.e., $\rho=(\cosh \alpha L(1-X) /$ $\cosh (\alpha L / 2))$.

Softening Zone $(0 \leq X \leq 0.5)$.

The substitution of $L_{s}=L / 2$ into Equation (54) results in $\tau_{s}(x)=\tau_{p}[\cos \beta((L / 2)-x)-((\beta \tanh (\alpha L / 2) / \alpha) \sin \beta((L / 2)$ $-x))$ ], i.e., $\rho=\cos \beta L(0.5-X)-((\beta \tanh (\alpha L / 2) / \alpha) \sin \beta L$ $(0.5-X))$.

From Equation (56), the critical tension of the elasticsoftening transition stage and the pure softening stage is $T_{s 0}^{c}=\left(2 \tau_{p} \sin \beta L / \beta\right)=10.03 \mathrm{kN} / \mathrm{m}$.

6.3.3. Pure Softening Stage. The substitution of Equation (59) results in $\tau_{s}(x)=R_{f} \tau_{p}(\tan \beta L \sin \beta x+\cos \beta x)$, i.e., $\rho=R_{f}(\tan \beta L \sin \beta L X+\cos \beta L X)$.

The critical tension of the pure softening stage and the softening-residual transition stage obtained by substitution of Equation (62) is $T_{s r 0}^{c}=\left(2 \tau_{p} \tan \beta L / \beta\right)=7.16 \mathrm{kN} / \mathrm{m}$. 
TABLE 5: Critical tensile force between the two stages of the softening pull-out model.

\begin{tabular}{|c|c|c|c|c|}
\hline Pull-out stage & I-II & II-III & III-IV & IV-V \\
\hline Critical tensile force & $T_{e s 0}^{c}=\left(2\left(\tau_{p}-\tau_{o}\right) \tanh \alpha L\right) / \alpha$ & $T_{s 0}^{c}=\left(2 \tau_{p} \sin \beta L\right) / \beta$ & $T_{s r 0}^{c}=\left(2 \tau_{r} \tan \beta L\right) / \beta$ & $T_{s 0}^{c}=2 \tau_{r} L$ \\
\hline
\end{tabular}

TABLE 6: Initial tensile forces at different stages of the softening pull-out model.

\begin{tabular}{lc}
\hline Pull-out stage & Initial tensile forces \\
\hline I & Elastic stage: $T_{01}=((2 \tanh \alpha L) / \alpha) k_{s 1} u_{e 0}$ \\
II & Elastic zone: $T_{02}=\left(2 \tau_{p} \tanh \alpha\left(L-L_{s}\right)\right) / \alpha$; softening zone: $T_{03}=2 \tau_{p}\left[\left(\left(\sin \beta L_{s} / \beta\right)+\left(\left(\tanh \alpha\left(L-L_{s}\right)\right) / \alpha\right) \cos \beta L_{s}\right)\right]$ \\
III & Softening stage: $T_{04}=(2 \tan \beta L / \beta)\left[k_{s 2}\left(u_{s 0}-u_{p}\right)+\tau_{p}\right]$ \\
IV & Softening zone: $T_{05}=\left(2 \tau_{r} \tan \beta\left(L-L_{r}\right)\right) / \beta ;$ residual zone: $T_{06}=\left(\left(2 \tau_{r} \tan \beta\left(L-L_{r}\right)\right) / \beta\right)+2 \tau_{r} L_{r}$ \\
V & - \\
\hline
\end{tabular}

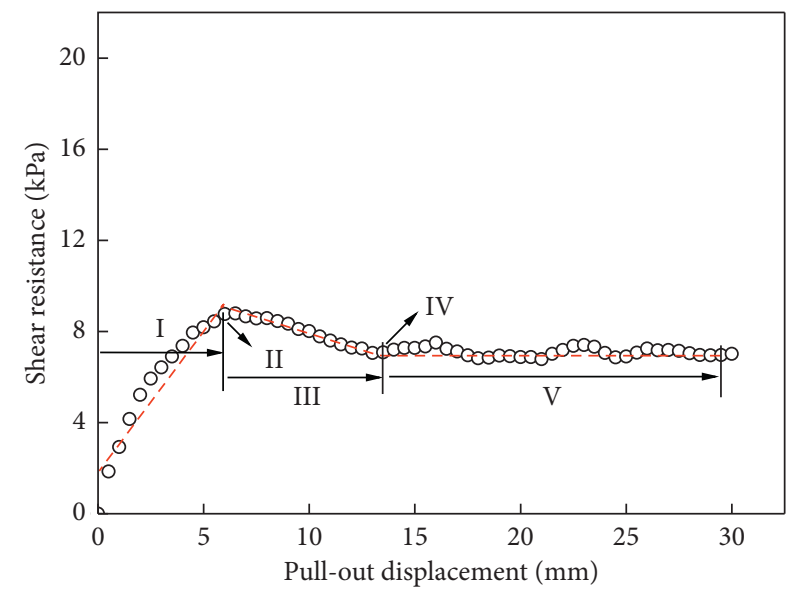

(a)

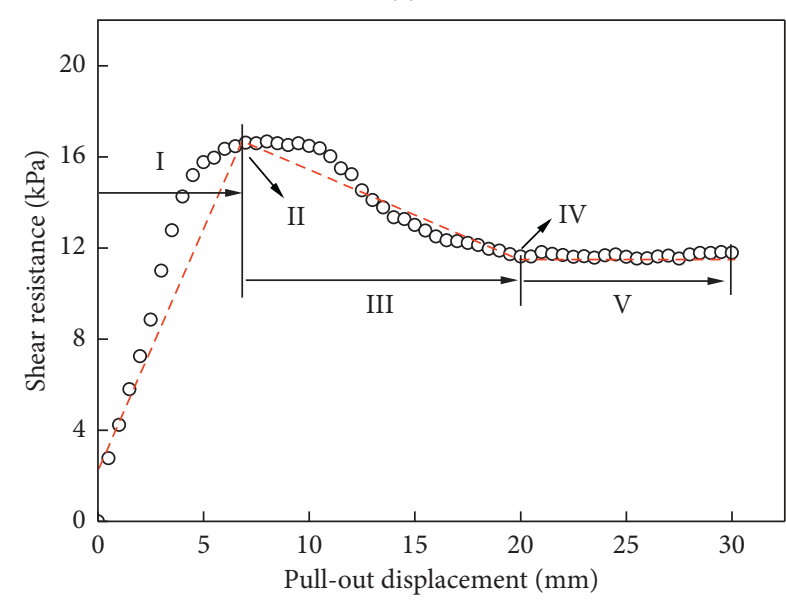

(c)

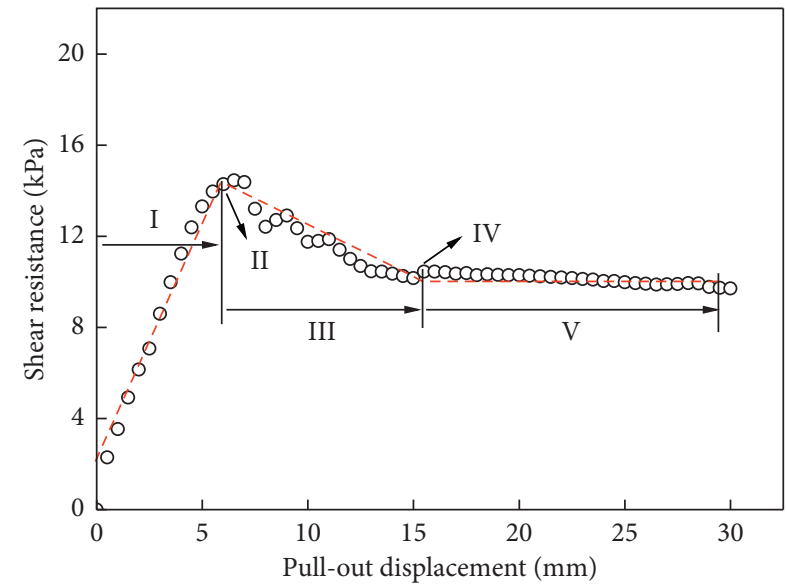

(b)

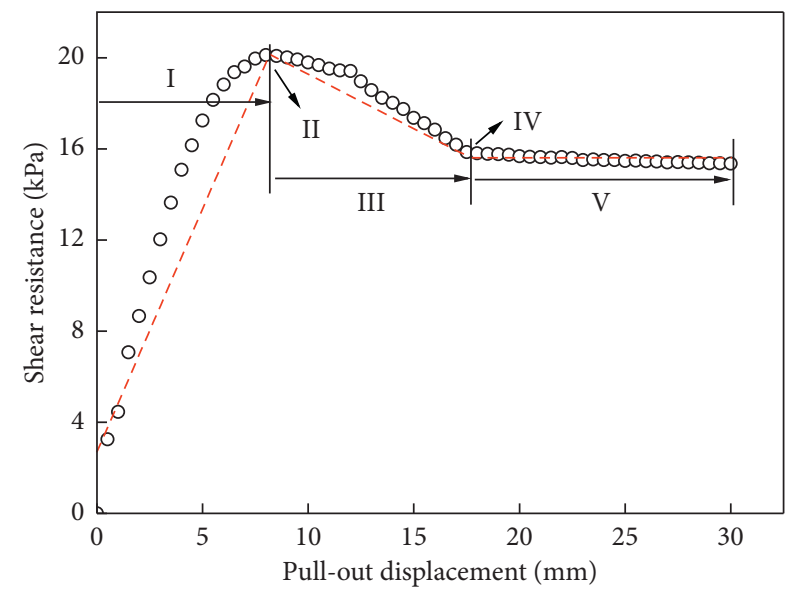

(d)

FIGURE 19: Comparison between the pull-out test results and model-predicted results of geotextiles under different normal stresses.

\subsubsection{Softening-Residual Transition Stage}

Softening Zone $(0.5 \leq X \leq 1)$.

The substitution of $L_{r}=L / 2$ into (64) results in $\tau_{s}(x)=\tau_{r}[\tan (\beta L / 2) \sin \beta(x-(L / 2))+\cos \beta(x-(L / 2))]$, i.e., $\rho=R_{f}[\tan (\beta L / 2) \sin \beta L(X-0.5)+\cos \beta L(X-0.5)]$.
Residual Zone $(0 \leq X \leq 0.5)$.

The interface shear stress entering the residual zone is $\tau_{r}(x)=R_{f} \tau_{p}$, i.e., $\rho=R_{f}=0.7$.

From Equation (70), the critical tension of the softeningresidual transition stage and the pure residual stage can be calculated to be $T_{s 0}^{c}=2 \tau_{r} L=7.06 \mathrm{kN} / \mathrm{m}$. 


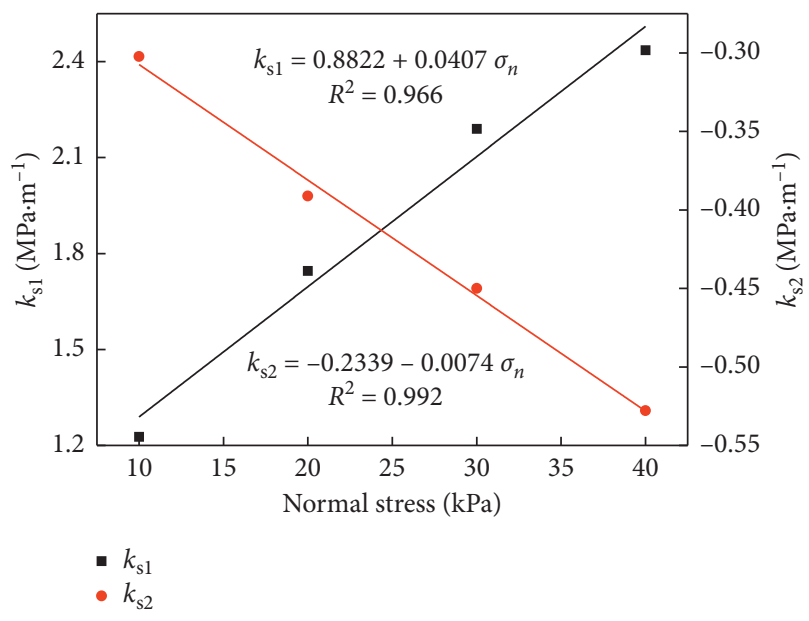

(a)

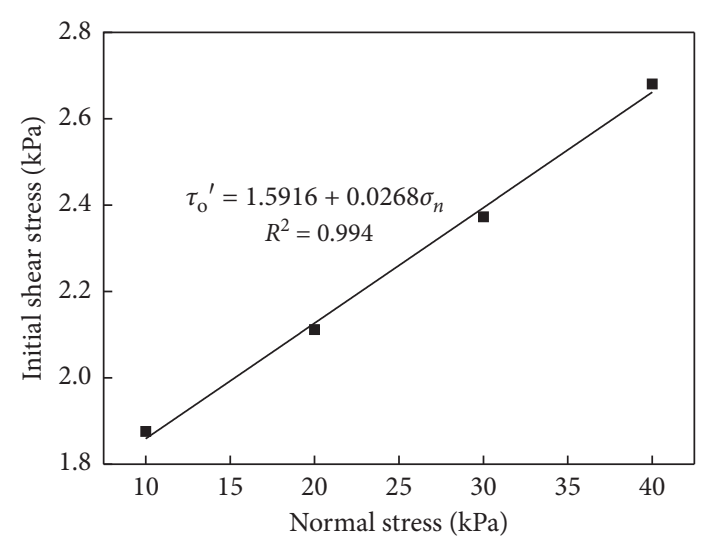

(b)

FIgURE 20: The relationship between the normal stress and the shear stiffness of the softening model: (a) shear stiffness and (b) initial shear stress.

TABLE 7: Softening model parameters.

\begin{tabular}{lccccccc}
\hline$\sigma_{n}(\mathrm{kPa})$ & $L(\mathrm{~m})$ & $t(\mathrm{~mm})$ & $E(\mathrm{GPa})$ & $k_{s 1}(\mathrm{MPa} / \mathrm{m})$ & $k_{s 2}(\mathrm{MPa} / \mathrm{m})$ & $f$ & $R_{f}$ \\
\hline 30 & 0.3 & 2 & 1 & 2.190 & -0.450 & 0.560 & 0.7 \\
\hline
\end{tabular}

6.3.5. Pure Residual Stage. In the pure residual stage, the interface shear stress is $\tau_{r}(x)=R_{f} \tau_{p}$, i.e., $\rho=R_{f}=0.7$.

According to the above expressions, the evolution laws of the pull-out interface shear stress in the elastic stage, the elastic-hardening transition stage, and the pure hardening stage of strain-softening reinforcement can be obtained, as shown in Figure 21. The graph shows the following.

When $T \leq 9.47 \mathrm{kN} / \mathrm{m}$, the interface is in the elastic stage, and the shear stress decreases nonlinearly from the pull-out end to the free end. At that time, the interface is in the critical stage of the elastic and elastic-softening transition, and the pull-out end reaches the peak shear stress of $16.8 \mathrm{kPa}$.

When $9.47 \mathrm{kN} / \mathrm{m} \leq T \leq 10.03 \mathrm{kN} / \mathrm{m}$, the interface is in the transition stage of elastic-softening, the shear stress first increases and then decreases, and the peak point is at the junction of the elastic zone and the softening zone. With increasing tension, the softening zone length increases, and the shear stress at the free end approaches the peak gradually. When $T=7.16 \mathrm{kN} / \mathrm{m}$, the free end shear stress also reaches the peak value, and the interface will enter the stage of pure softening.

When $7.16 \mathrm{kN} / \mathrm{m} \leq T \leq 10.03 \mathrm{kN} / \mathrm{m}$, the interface is in the pure softening stage, and the shear stress increases nonlinearly from the pull-out end to the free end. When $T=7.16 \mathrm{kN} / \mathrm{m}$, the shear stress at the pull-out end reaches the residual stress, and the interface will enter the softeningresidual transition stage.

When $7.06 \mathrm{kN} / \mathrm{m} \leq T \leq 7.16 \mathrm{kN} / \mathrm{m}$, the interface is in the softening-residual transition stage. In this stage, the pull-out end begins to enter the residual state and gradually transits to the free end. When $T=7.06 \mathrm{kN} / \mathrm{m}$, the free end also reaches the residual stress, and the interface will enter the pure residual stage.

When $T=7.06 \mathrm{kN} / \mathrm{m}$, the shear stress remains unchanged when the interface is in the pure residual stage.

6.4. Parametric Impact Analysis. The results show that the interface shear stress is mainly affected by the elastic shear stiffness $\left(k_{s 1}\right)$ and the single-width tensile stiffness $(E t)$ in the elastic stage. The distribution of the shear stress in the softening stage and the residual stage is related to the length of the softening zone $\left(L_{s}\right)$, the softening shear stiffness $\left(k_{s 2}\right)$, the residual interval length $\left(L_{r}\right)$, the elastic shear stiffness $\left(k_{s 2}\right)$, and the failure ratio $R_{f}$ of the reinforcement. The calculated parameters are consistent with the previous section. The ratio of the softening zone length to reinforcement length is defined as $\eta=L_{s} / L$, and the ratio of residual zone length to the reinforcement length is defined as $\xi=L_{r} / L$.

6.4.1. Elastic Stage. The variation in the interface shear stress of the strain-softening reinforcement in the elastic stage is consistent with that of the strain-hardening reinforcement at this stage, which has not been thoroughly described here.

6.4.2. Elastic-Softening Transition Stage. The influence of the softening zone length $L_{s}(\eta)$ on the interface shear stress at different locations of the reinforcement in stage II is shown in Figure 22. It can be found from the graph that the interface shear stress in stage II increases first and then decreases from the pull-out end to the free end, and the peak 


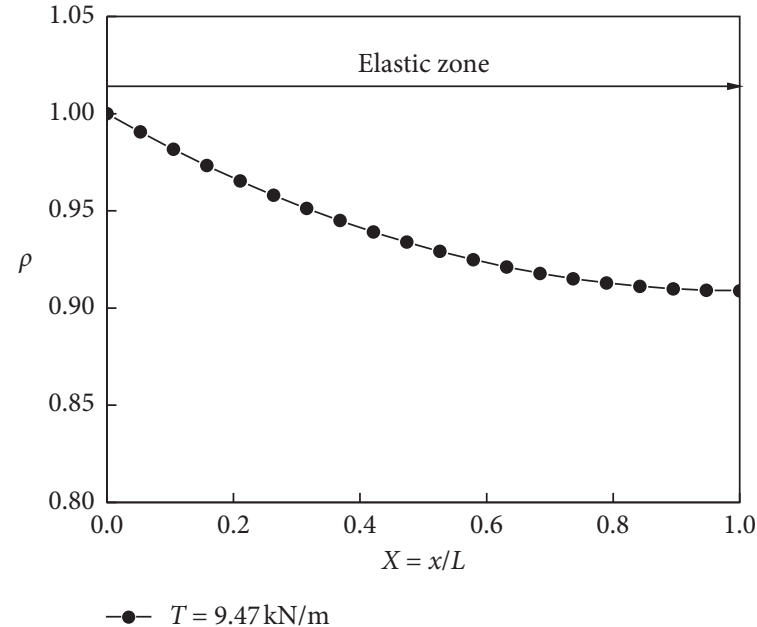

(a)

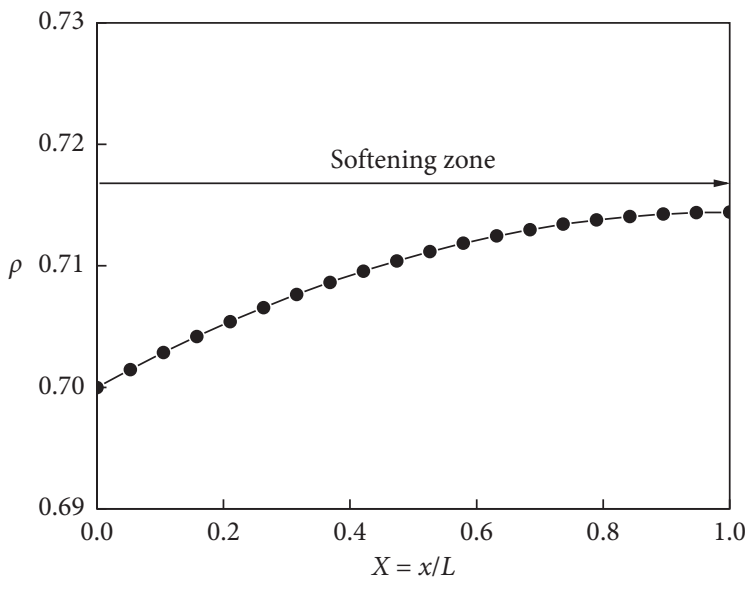

$-\bullet-T=7.16 \mathrm{kN} / \mathrm{m}$

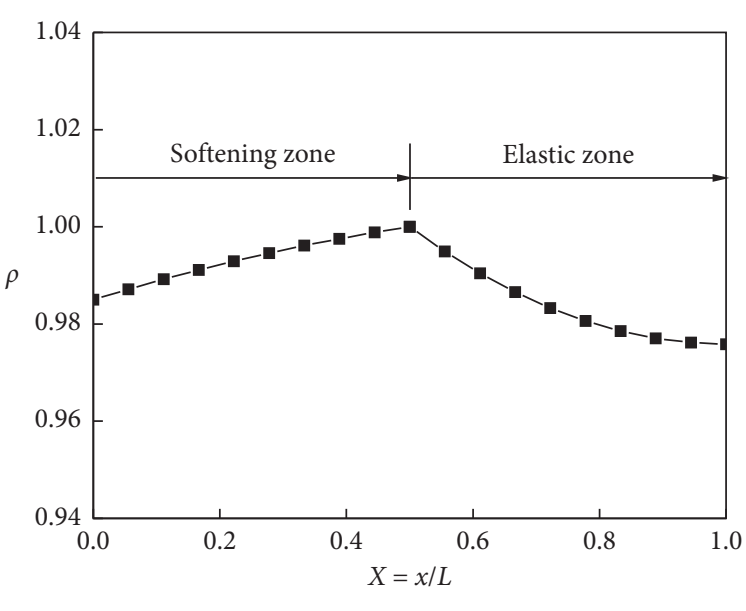

$-\square-T=10.03 \mathrm{kN} / \mathrm{m}$

(b)

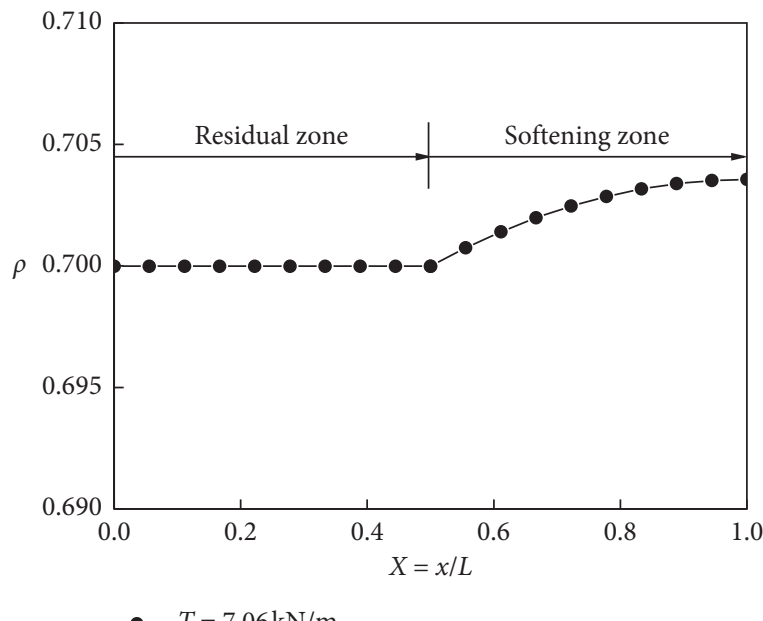

(d)

(c)

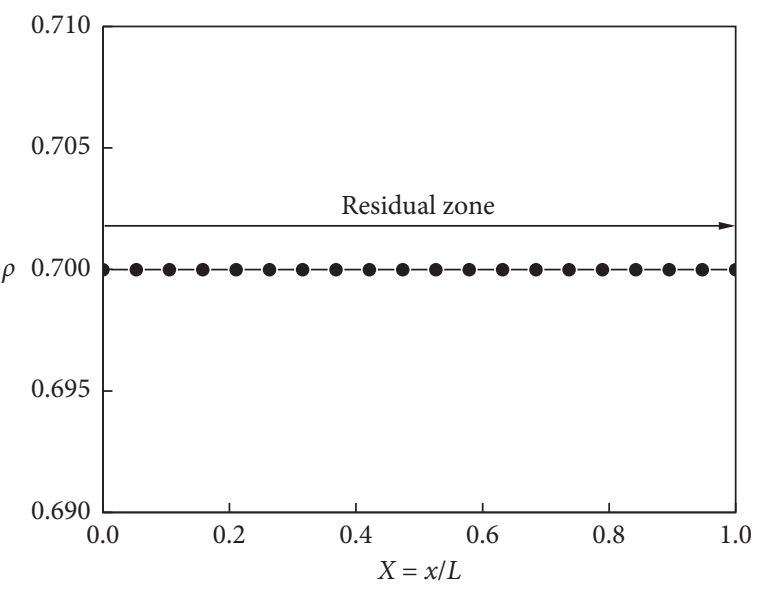

$T=7.06 \mathrm{kN} / \mathrm{m}$

(e)

FiguRE 21: Evolution of the interfacial shear stress in the different stages of the pull-out process of the reinforced tailings (strain-softening reinforcement): (a) elastic stage; (b) elastic-softening transition stage; (c) pure softening stage; (d) softening-residual transition stage; and (e) pure residual stage. 


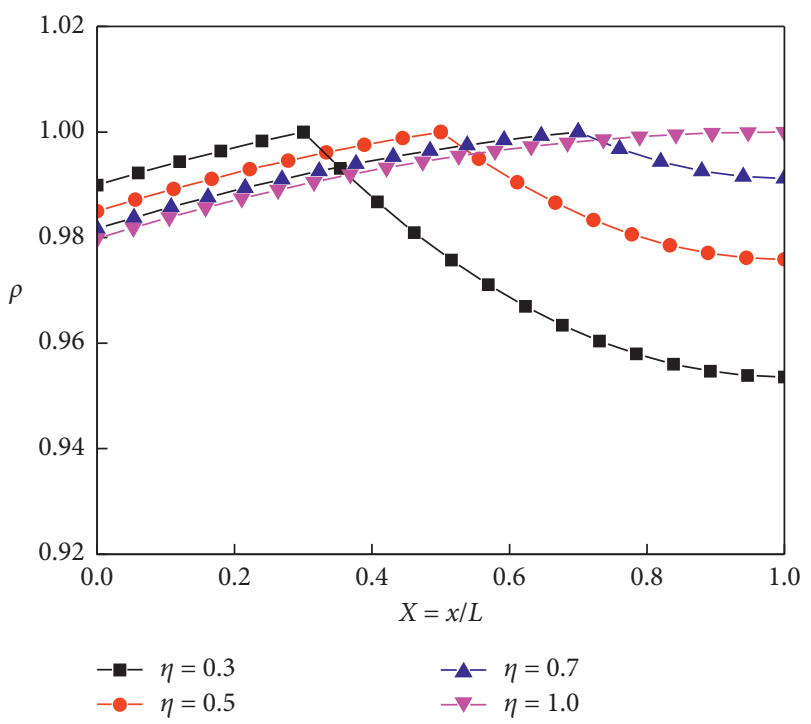

FIGURE 22: Effect of the interface frictional resistance at stage II on $L_{s}$.

value is at the critical point of the elastic zone and the softening zone in stage II. With an increase in $\eta$, the peak value of the interface shear stress gradually transfers to the free end.

As shown in Figure 23, the effect of the softening shear stiffness $\left(k_{s 2}\right)$ on the interface shear stress at different locations of the reinforcement in stage II is studied. It can be seen from the graph that $k_{s 2}$ only affects the change in the shear stress of the softening zone in stage II but has no effect on the shear stress of the elastic zone. The larger the $k_{s 2}$ is, the larger the range of the interface shear stress changes is, which indicates that the softening characteristics of the reinforcement are more obvious.

6.4.3. Pure Softening Stage. As shown in Figure 24, the effect of the softening shear stiffness $\left(k_{s 2}\right)$ on the interface shear stress at different locations of the steel bars in stage III was studied. It can be found from the graph that the interface shear stress increases nonlinearly from the pull-out end to the free end. The shear stress at the pull-out end is the smallest, and the shear stress at the free end is the largest. At this time, the shear stress at the pull-out end has been reduced to the residual stress.

6.4.4. Softening-Residual Transition Stage and Pure Residual Stage. As shown in Figure 25, the effect of the softening shear stiffness $\left(k_{s 2}\right)$ on the interface shear stress at different locations of the steel bars in stage IV is studied. It can be seen from the figure that $k_{s 2}$ only affects the change in the shear stress of the residual zone in stage IV, in which the softening zone decreases to the residual stress. The larger the $k_{s 2}$ is, the greater the nonlinear increase in the interface shear stress is.

As shown in Figure 26, the effect of the residual zone length $L_{r}(\xi)$ on the interface shear stress at different locations of the reinforcement in stage IV was studied. It can be seen from the graph that the interface shear stress is the

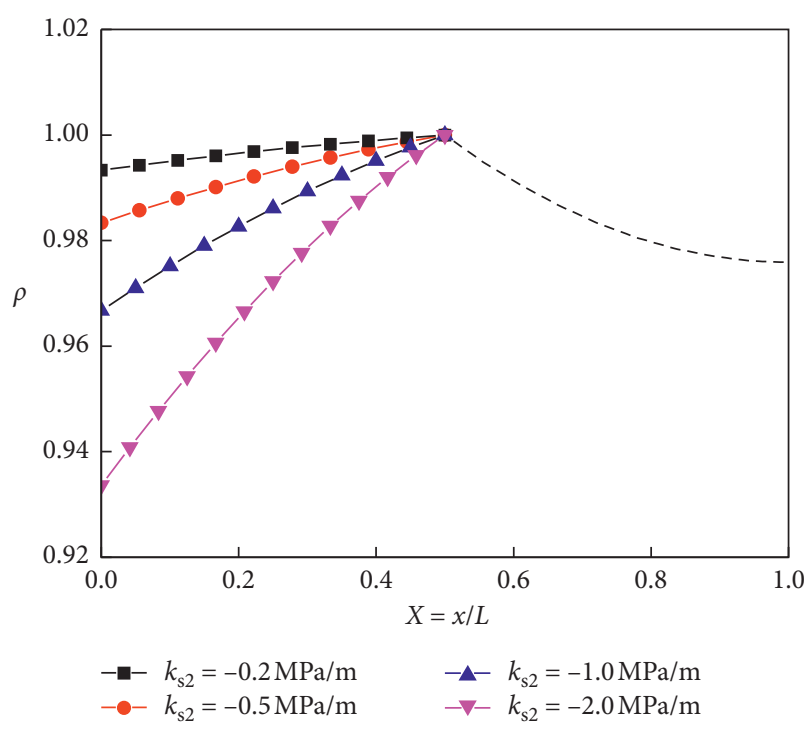

Figure 23: Effect of the interface frictional resistance at stage II on $k_{s 2}$.

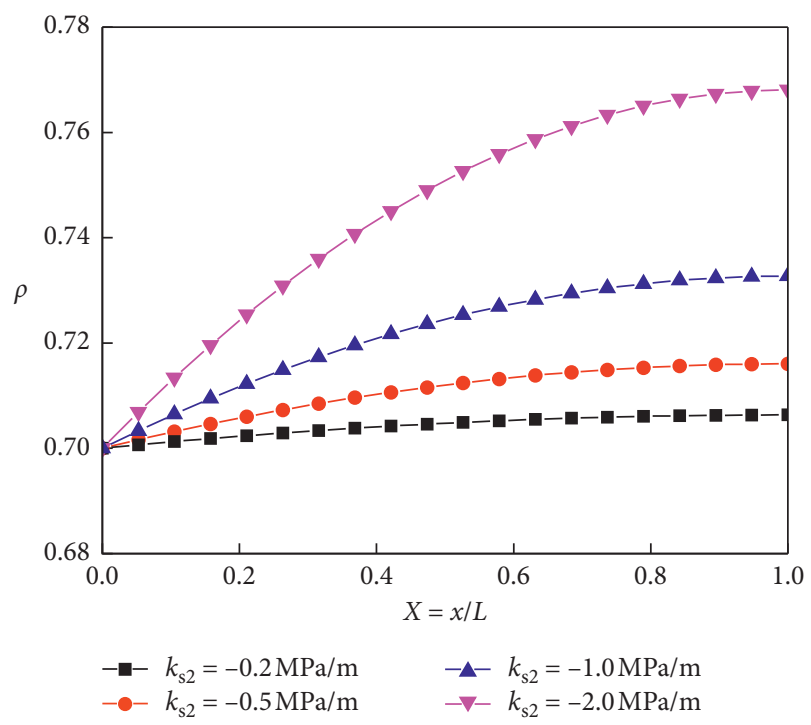

FIGURE 24: Effect of the interface frictional resistance at stage III on $k_{s 2}$.

smallest at the critical point between the softening zone and the residual zone in stage IV; at this time, the shear stress is the residual stress. The shear stress at the free end is the largest, which indicates that the interface friction of the reinforcement in the softening zone can more easily play a role, and the shear stress at the free end increases. With an increase in the residual zone length, the interface gradually transitions from the softening-residual stage to the pure residual stage. The distribution of the shear stress tends to be constant. The interface completely enters the residual stage, and the shear stress presents a horizontal distribution. That is, when the interface shear stress decreases to the residual stress, it will not change and will be in a plastic flow state, which is in accordance with the assumption. 


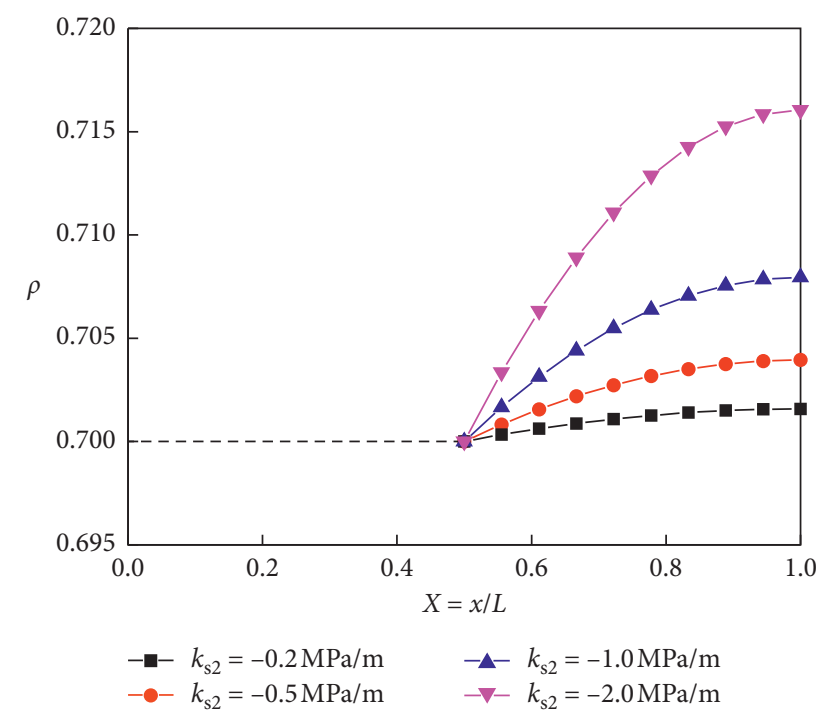

FIGURE 25: Effect of the interface frictional resistance at stage IV on $k_{s 2}$.

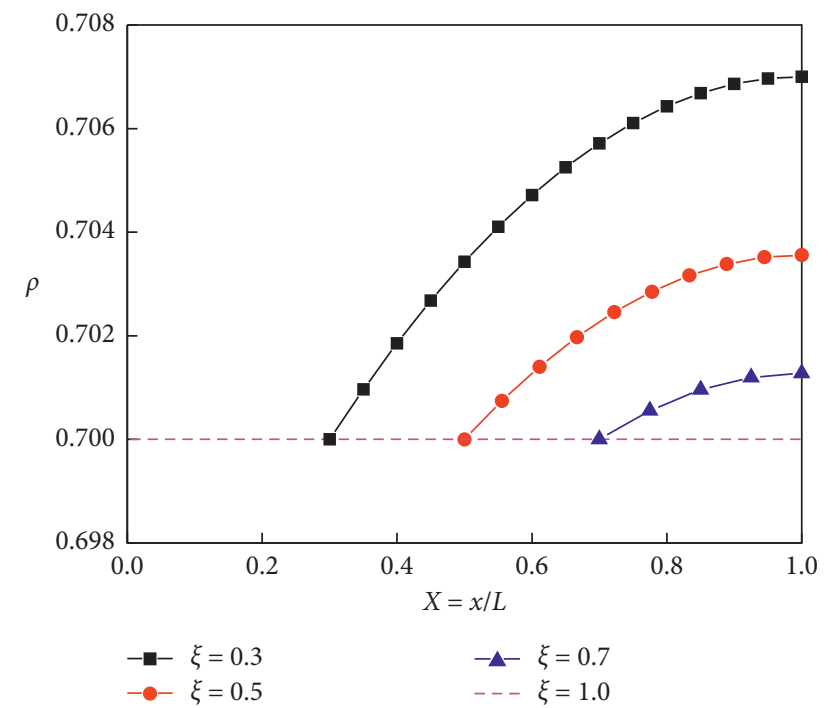

FIgURE 26: Effect of the interface frictional resistance at stage IV on $L_{r}$.

\section{Conclusions}

(1) The pull-out test curves of the geogrids and tailings show strain-hardening characteristics, and the pullout test curves of the geotextiles and tailings show strain-softening characteristics. In addition, both kinds of pull-out curves require a certain pull-out force at the beginning of pull-out because the reinforcement requires a certain pull-out force to resist the friction of the interface between the reinforcement and tailings.

(2) Considering that the initial pull-out force is required in the initial pull-out process, a bilinear shear stressdisplacement hardening model and a trilinear shear stress-displacement softening model are proposed.
The pull-out process of the hardening reinforcement is divided into the elastic stage, the elastic-hardening transition stage, and the pure hardening stage. The pull-out process of softening reinforcement is divided into the elastic stage, elastic-softening transition stage, pure softening stage, softening-residual transition stage, and pure residual stage. Based on the interface basic governing equation, the analytical solutions of the interface tension, shear stress, and displacement at different stages under the pull-out load are derived, which satisfactorily reflect the progressive failure of the reinforcement-tailing interface.

(3) The predicted results of the two models are basically in agreement with the pull-out test data, which verifies the validity of the proposed two elasticplastic models for the progressive failure analysis of the reinforcement at the pull-out interface; in the pull-out process, the general transition stage is not obvious. The new linear shear stress-displacement hardening and softening model is simple, easy to calculate, and has good applicability and can be used in the study of the characteristics of pull-out interfaces.

(4) In the pull-out process of the reinforcement, when the reinforcement is in the elastic stage, the nonlinearity and maximum value of the interface shear stress increase with an increase in the elastic shear stiffness, while the tensile stiffness is the opposite. When the reinforcement is in the hardening stage or the softening stage, the larger the hardening (softening) shear stiffness is, the larger the change in the range of the shear stress is and the more obvious the hardening (softening) characteristics of the reinforcement are.

\section{Data Availability}

The data used to support the findings of this study are included within the article.

\section{Conflicts of Interest}

The authors declare that there are no conflicts of interest regarding the publication of this paper.

\section{Acknowledgments}

The research was supported by the National Natural Science Foundation of China (51774163) and the Scientific Research Project of Angang Group (2018, Ke-A19).

\section{References}

[1] G. L. S. Babu, A. Sridharan, and K. K. Babu, "Composite reinforcement for reinforced soil applications," Journal of the Japanese Geotechnical Society of Soils and Foundations, vol. 43, no. 2, pp. 123-128, 2003.

[2] T. Nakamura, T. Mitachi, and I. Ikeura, "Estimating method for the in-soil deformation behavior of geogrid Based on the 
results of direct box shear test," Journal of the Japanese Geotechnical Society of Soils and Foundations, vol. 43, no. 1, pp. 47-57, 2003.

[3] D. D. Shi, W. B. Liu, and W. H. Shui, "Comparative experimental studies of interface characteristics between uniaxial/ biaxial plastic geogrids and different soils," Rock and Soil Mechanics, vol. 30, no. 8, pp. 2237-2244, 2009.

[4] G. Q. Yang, G. X. Li, and B. J. Zhang, "Experimental studies on interface friction characteristics of geogrids," Chinese Journal of Geotechnical Engineering, vol. 28, no. 8, pp. 948-952, 2006.

[5] A. Sawicki, "Modelling of geosynthetic reinforcement in soil retaining walls," Geosynthetics International, vol. 5, no. 3, pp. 327-345, 1998.

[6] M. Abramento and A. J. Whittle, "Analysis of pullout tests for planar reinforcements in soil," Journal of Geotechnical Engineering, vol. 121, no. 6, pp. 476-485, 1995.

[7] Z. Yuan, "Pullout response of geosynthetic in soil-theoretical analysis," in Proceedings of the Geo-Frontiers Congress, Dallas, TX, USA, March 2011.

[8] N. Gurung, "1-D analytical solution for extensible and inextensible soil/rock reinforcement in pull-out tests," Geotextiles and Geomembranes, vol. 19, no. 4, pp. 195-212, 2001.

[9] C. Huang, H. Hsieh, and Y. Hsieh, "Hyperbolic models for a 2-D backfill and reinforcement pullout," Geosynthetics Internationa, vol. 21, no. 3, pp. 168-178, 2014.

[10] E. M. Palmeira, "Bearing force mobilisation in pull-out tests on geogrids," Geotextiles \& Geomembranes, vol. 22, no. 6, pp. 481-509, 2004.

[11] S. Sobhi and J. T. H. Wu, "An interface pullout formula for extensible sheet reinforcement," Geosynthetics International, vol. 3, no. 5, pp. 565-582, 1996.

[12] P. V. Long, D. T. Bergado, A. S. Balasubramaniam et al., "Interaction between soil and geotextile reinforcement," American Society of Civil Engineers, Geotechnical Special Publication, vol. 69, pp. 560-578, 1997.

[13] N. Gurung, Y. Iwao, and M. R. Madhav, "Pullout test model for extensible reinforcement," International Journal for $\mathrm{Nu}$ merical and Analytical Methods in Geomechanics, vol. 23, no. 12, pp. 1337-1348, 1999.

[14] A. Misra, C. H. Chen, R. Oberoi et al., "Simplified analysis method for micropile pullout behavior," Journal of Geotechnical and Geoenvironmental Engineering, vol. 130, no. 10, pp. 1024-1033, 2004.

[15] N. Gurung, "A theoretical model for anchored geosynthetics in pull-out tests," Geosynthetics International, vol. 7, no. 3, pp. 269-284, 2000.

[16] J. J. B. Esterhuizen, G. M. Filz, and J. M. Duncan, "Constitutive behavior of geosynthetic interfaces," Journal of Geotechnical and Geoenvironmental Engineering, vol. 127, no. 10, pp. 834-840, 2001.

[17] W. A. Lin, B. Zhu, Y. M. Chen et al., "Tension analysis of geomembrane in landfill slope considering interface strainsoftening," Rock and Soil Mechanics, vol. 29, no. 8, pp. 2063-2069, 2008.

[18] P. Zhang, J. H. Wang, and J. J. Chen, "Mechanical behavior of the interface between reinforcement and soil in pull-out tests on geotextiles," Journal of Shanghai Jiaotong University, vol. 38, no. 6, pp. 999-1002, 2004.

[19] C. Y. Hong, J. H. Yin, W. H. Zhou, and H.-F. Pei, "Analytical study on progressive pullout behavior of a soil nail," Journal of Geotechnical and Geoenvironmental Engineering, vol. 138, no. 4, pp. 500-507, 2012.
[20] H. H. Zhu, C. C. Zhang, C. S. Tang et al., "Modeling the pullout behavior of short fiber in reinforced soil," Geotextiles and Geomembranes, vol. 42, no. 4, pp. 329-338, 2014.

[21] J. Chen, S. Saydam, and P. C. Hagan, "An analytical model of the load transfer behavior of fully grouted cable bolts," Construction and Building Materials, vol. 101, no. 1, pp. 1006-1015, 2015.

[22] Ministry of Transport of the People's Republic of China, "Test models of geosynthetics for highway engineering, JTG E502006," Communication Press, Beijing, China, 2006.

[23] M. R. Madhav, N. Gurung, and Y. Iwao, "A theoretical model for pull-out response of extensible reinforcements," Geosynthetics International, vol. 5, no. 4, pp. 399-424, 1998.

[24] F. W. Lai, L. P. Li, and F. Q. Chen, "Elastic-exponential softening model for behavior of interface between geogrid reinforcement and soil against pullout," Journal of Engineering Geology, vol. 26, no. 4, pp. 852-860, 2018.

[25] M. Yang, N. Li, X. X. Liu et al., "Experimental research on interface frictional behaviors of the geotextile-reinforced soil," Journal of Xi'an University of Technology, vol. 32, no. 1, pp. 46-51, 2016. 